\title{
Hydrothermal Synthesis and Characterization of Zeolite A from Corn (Zea Mays) Stover Ash
}

\author{
Norway Pangan $1,2, * \mathbb{0}$, Susan Gallardo ${ }^{2}$, Pag-asa Gaspillo ${ }^{2}$, Winarto Kurniawan ${ }^{3}$, Hirofumi Hinode ${ }^{3}$ \\ and Michael Promentilla ${ }^{2}$ D \\ 1 Arts and Sciences Department, Technological University of the Philippines, Taguig 1630, Philippines \\ 2 Chemical Engineering Department, De La Salle University of the Philippines, Manila 0922, Philippines; \\ susan.gallardo@dlsu.edu.ph (S.G.); pag-asa.gaspillo@dlsu.edu.ph (P.-a.G.); \\ michael.promentilla@dlsu.edu.ph (M.P.) \\ 3 Department of International Development Engineering, Tokyo Institute of Technology, Tokyo 152-8550, Japan; \\ kurniawan.w.ab@m.titech.ac.jp (W.K.); hinode.h.aa@m.titech.ac.jp (H.H.) \\ * Correspondence: norway_pangan@tup.edu.ph; Tel.: +63-917-117-7939
}

Citation: Pangan, N.; Gallardo, S.; Gaspillo, P.-a.; Kurniawan, W.; Hinode, H.; Promentilla, M.

Hydrothermal Synthesis and

Characterization of Zeolite A from Corn (Zea Mays) Stover Ash. Materials 2021, 14, 4915. https:// doi.org/10.3390/ma14174915

Academic Editors: Alain Moissette and Serena Esposito

Received: 14 July 2021

Accepted: 27 August 2021

Published: 29 August 2021

Publisher's Note: MDPI stays neutral with regard to jurisdictional claims in published maps and institutional affiliations.

Copyright: (C) 2021 by the authors. Licensee MDPI, Basel, Switzerland. This article is an open access article distributed under the terms and conditions of the Creative Commons Attribution (CC BY) license (https:/ / creativecommons.org/licenses/by/ $4.0 /)$.

\begin{abstract}
This study deals with the impact of calcination, alkalinity, and curing time parameters on the hydrothermal synthesis of zeolite A. The zeolite A sample, produced from corncob-stalkand-leaves (corn stover) ash was characterized using X-ray diffraction (XRD), Fourier transform infrared spectroscopy (FT-IR), thermo-gravimetric analysis (TGA), and scanning electron microscopy (SEM). The results showed that calcination, alkalinity, and curing time have significant effects on the crystallization and the morphology of zeolite A. In addition, these parameters also impacted the cation exchange capacity. Furthermore, the synthesized zeolite A was obtained using a calcination temperature of $500{ }^{\circ} \mathrm{C}$ within two hours of airflow, which is much lower than the temperatures previously reported in the literature for an agricultural waste and other waste materials. A fusion ratio of corn stover ash: $\mathrm{NaOH}$ of 1.0:1.5 and a curing time of nine hours were achieved. This is a major result as this curing time is much lower than those featured in other studies, which can reach up to twenty-four hours. In this paper, cubic crystal with rounded edge of zeolite A, having a cation exchange capacity of 2.439 meq $\mathrm{Na}^{+} / \mathrm{g}$ of synthesized anhydrous zeolite A, was obtained, which can be a good candidate for ion-exchange separation.
\end{abstract}

Keywords: hydrothermal synthesis; corn stover ash; zeolite A; calcination; alkalinity; curing time; cation exchange capacity

\section{Introduction}

The Philippines is recognized for its agricultural contributions. In spite of the aim to create a highly urbanized and industrialized country out of the archipelago, a major part of the Philippine economy still relies on agriculture as the people's primary livelihood. People in the rural areas of the country still support themselves through agriculture-farming, livestock, forestry, and fisheries. Statistics show that these four sub-sectors of agriculture together represent 38.9 percent of labor employment, thereby contributing twenty percent of the country's gross domestic product (GDP) [1,2]. Corn is the second leading Philippine agricultural yield next to rice, with one third of Philippine farmers depending on corn as their significant source of income. Reports state that corn is one major staple substitute in cases of rice scarcity, and is a primary source of animal industry feed in the country. Corn is also gaining popularity in terms of usage in manufacturing [3].

It is thus safe to say that corn is an important agricultural product in the country. Corn could therefore possibly create mounting agricultural residues; it is estimated that the Philippines can produce a million ton of corn cobs annually [4,5]. The chief components of a corn are the corn grain and corn stover (the corn cob, stalk, and leaves). The 1:1 ratio of grain:stover accounts for a slight rise in the weight of the stover in the total biomass 
produced by a given corn farm. The burning process usually carried out in a corn farm, producing a corn stover as a by-product in which the corncob, stalk and leaves are burned at temperatures of $800{ }^{\circ} \mathrm{C}$ to $1000{ }^{\circ} \mathrm{C}$. Corn stover ash is of a spongy and porous structure by nature. Twenty percent of the weight of a corn stover is represented by the corn cob [6] and consists of a huge amount of lignocelluloses materials. Some farmers use corn stover as feeds for their animals; others burn these as wastes. The ash produced after burning requires definitive and permanent disposal. The main chemical composition of corncobstalk-and-leaves (corn stover) ash is silica. The synthesis of zeolites, which are obtained from the combustion of ash particles, would therefore be an ideal application in this area, since these ash materials are inexpensive and available in abundance.

Generally, published works [7-9] have revealed that the major silica precursors used are commercially-made alkoxysilane compounds such as sodium silicate, tetraethyl orthosilicate (TEOS), and tetramethyl orthosilicate. However, Nakashima et al. [10] stated that close contact with a certain type of alkoxysilane compounds could lead to death. Numerous researchers have reported that it is expensive to produce synthetic zeolites from alkoxysilane chemical sources; however, commercial silica is available in different forms (amorphous solid, fume, gel, and sol) and is found to be cheaper but has unpredictable reactivity and selectivity [11]. Thus, there is a need to look for an ecological, inexpensive, and non-toxic silica precursor. Naturally occurring silicas found in agricultural waste are a good substitute for commercial silica precursors. Thus, raw materials from agricultural waste, such as corncob-stalk-and-leaves ash [12], rice husk ash [13-24], sugar cane bagasse ash [25,26], barley ash [27], coal ashes [28-34], clay minerals [35-40], industrial slags [41], natural zeolites [42], and solid waste incineration ashes [43-45], are used as alternative and cheap source materials for the synthesis of zeolite. The use of agricultural waste materials, such as those in the field of water purification and in the removal of ammonium or heavy metals, makes them appealing as useful products that contribute to the mitigation of environmental problems. They are even more appealing now that the limited capacity of available landfills have caused environmental and social problems, arising from the growing amount of solid waste from the day-to-day living of the population.

Several studies have been carried out using the above-mentioned agricultural waste materials for the synthesis of zeolite. However, no studies have been conducted using corn stover ash in synthesizing zeolites, particularly zeolite A. This study specifically deals with synthesizing zeolite A from corn stover ash-specifically synthesizing zeolite A that shows the Linde type A (LTA) structure. The zeolite A pore has three-dimensional aluminosilicates that are perpendicular to each other in the $\mathrm{x}, \mathrm{y}$, and $\mathrm{z}$ planes. Its structure contains pores running perpendicular to each other in the $\mathrm{x}, \mathrm{y}$, and $\mathrm{z}$ planes, with an eightmember oxygen ring diameter that is small, at $4.2 \AA$, and a minimum of $11.4 \AA$ larger free cavity diameter [46]. The square-faced cubic structure surrounding the cavity is connected by eight sodalite cages. The zeolite $\mathrm{A}$ is fascinating due to its useful spacio-specific catalysis super-cage structure. There is a large enough structure in the inner cavity for varying reactions to take place, while only a specific structure can get into the small pore $[47,48]$.

Zeolites are increasingly popular in terms of their numerous technical applications, including as adsorbents, catalysts and ion exchangers, and separators $[18,26,44,49]$. The traditional applications of zeolite A for alternate zeolite production are as follows-the zeolite, when synthesized, can be applied as a precursor for making other zeolite materials such as zeolite N [50] and SSZ-13 [51]; for anti-bacterial and medical purposes such as the atomic resolution imaging of silver exchange zeolite $\mathrm{A}$ [52] and as a mineral-based hemostatic agent [53]; for catalytic processes such as the selective catalytic reduction of $\mathrm{NO}_{\mathbf{x}}$ [54,55], the production of biodiesel [56], oxidation reactions [57], and nitrous oxide $\left(\mathrm{N}_{2} \mathrm{O}\right)$ decomposition [58]; and for membrane separation. In addition to these applications, zeolite A is employed in the development of inorganic membranes to replace organic membranes, which has garnered popularity because of its potent benefits in terms of structural stability even when heated, more sturdy mechanical strength, and much improved resistance to chemicals, such as water permeability [59] and natural gas dehydration [60]. It is also used 
for water softening applications - used as softener for reverse osmosis brine or simulated seawater [61] and is also utilized in the detergent industry to improve the removal of both calcium and magnesium [62]. The most significant characteristic of zeolite $\mathrm{A}$ is the fact that it is now widely used in ion exchange separation, for example, in wastewater treatment, where zeolite A is found to have a variety of applications in ion exchange or the adsorption of range water contaminants such as ammonium ions [63], lead, copper [64], and nickel ions [65], as well as malachite green dyes [66] and oil-water [67].

The chemical and physical properties of zeolite A are largely related to their morphology, structure, and size distribution, and they also have significant effect on their applications and properties. Recent developments in this area have shown that zeolite A's mechanism of nucleation and the parameters of hydrothermal synthesis have a definite impact on the size of the crystal and the morphology of zeolite A, for example, the calcination, alkalinity and curing time that are utilized during the hydrothermal synthesis. Research results have shown that zeolite A morphology results from the reaction mixture of the chemical composition, specifically alkalinity. In addition to this, the preceding studies indicated that the above-stated parameters have caused the transformation phase of zeolite A to sodalite.

The current work pertains to the synthesis of zeolite A from corn stover ash that was revealed to be a source of silica when the amorphous form was extracted through the milling, calcining, and acid leaching of ash. A close study is essential in order to determine the effects of these parameters' (such as calcination, alkalinity, and curing time) on the cation exchange capacity, morphology, and particle size for hydrothermal synthesis. Likewise, characterizations of corn stover ash were investigated, including elemental analysis, Xray fluorescence $(\mathrm{XRF}), \mathrm{X}$-ray diffraction (XRD), Fourier transform infrared spectroscopy (FT-IR), thermo-gravimetric analysis (TG-DTA), and scanning electron microscopy (SEM).

\section{Materials and Methods}

\subsection{Sources of Raw Materials}

The corn stover ash from a corn producer in Ilocos Norte, Luzon, Philippines, was used as a raw material. The mechanical, thermal, and acid treatments are considered the pre-treatment processes of corn stover as shown in Figure 1. Corn stover was milled to particle sizes smaller than $0.0741 \mathrm{~mm}$ during the mechanical treatment. Next, the corn stover was calcined at an air flow rate of $100 \mathrm{~mL} / \mathrm{min}$ at various temperatures $(300,400$, $500,600,700^{\circ} \mathrm{C}$ ) for two hours to eliminate any incorporated organic matter for the thermal treatment. Finally, an acid-leached treatment was applied, with a $1.0 \mathrm{M} \mathrm{HCl}$ solution at $100{ }^{\circ} \mathrm{C}$ for an hour to the calcined corn stover. The solid/liquid ratio of calcined ash to acid was $1.0 \mathrm{~g} / 5 \mathrm{~mL}$. The metallic impurities in agricultural waste can be reduced to negligible concentrations by treating with hydrochloric acid $[68,69]$.

All chemicals were directly used as received without any further purification and are of analytical grade, obtained from Wako Pure Chemical Industries, Ltd., Japan. The aluminum source for zeolite A synthesis was sodium aluminate $(0.78$ molar ratio of $\mathrm{Al} / \mathrm{NaOH})$. The sodium source used was sodium hydroxide powder $(97.0 \%)$. Hydrochloric acid (1 M) was used for acid treatment. 

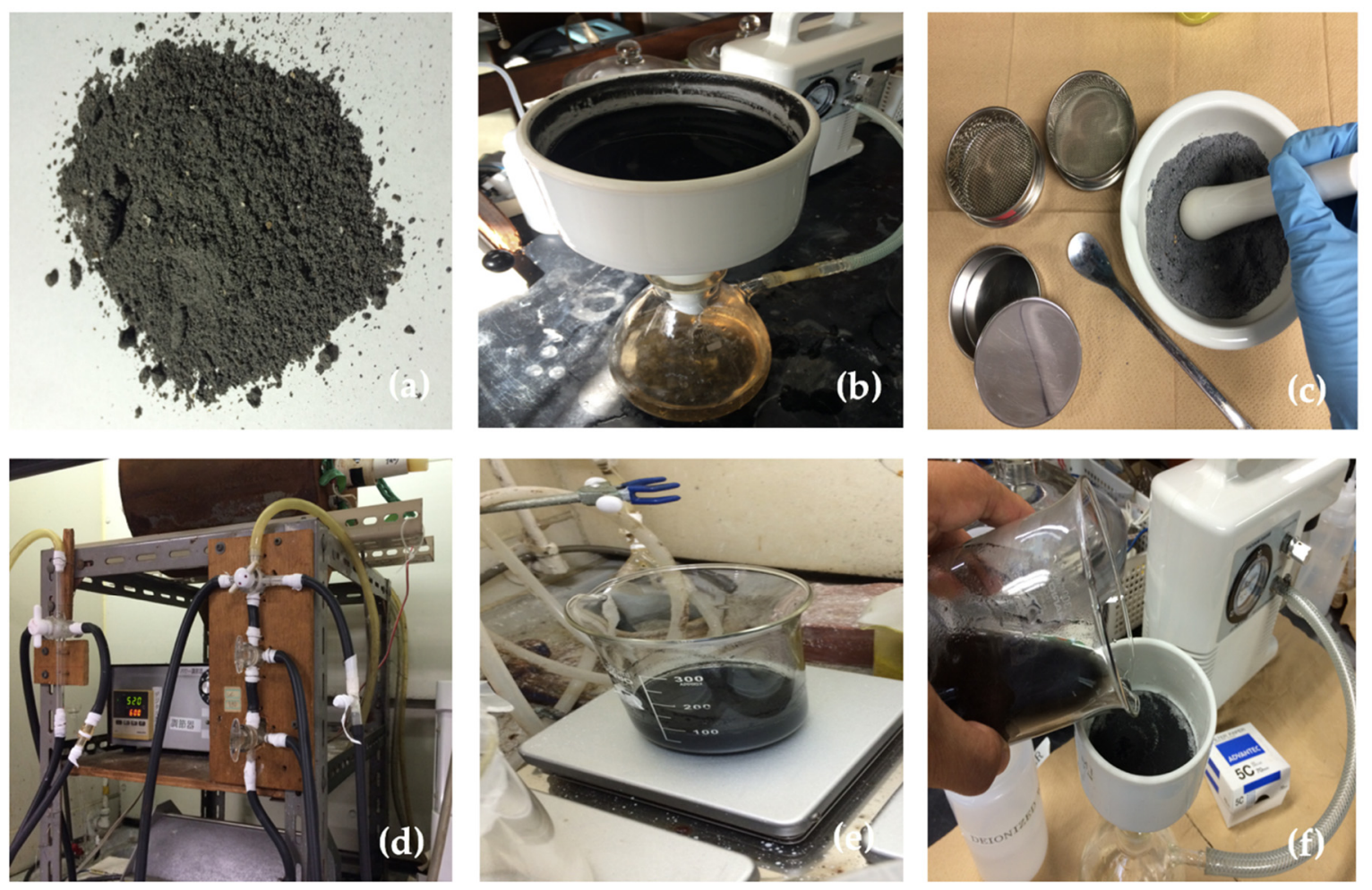

Figure 1. Corn stover ash from Ilocos Norte, Philippines: (a) as received; (b) the actual washing of corn stover; (c) the milling of corn stover; (d) the calcination of corn stover; (e) the acid treatment of corn stover; and, (f) the final washing of corn stover.

\subsection{Methods}

A two-step zeolite A preparation method was employed as illustrated in Figure 2, which encapsulates the scheme that consists of silica extraction and zeolite A production.

\subsubsection{Silica Extraction from Corn Stover Ash}

The first preparation step was the extraction of the silicon and aluminum content from corn stover particles. A fine fraction of pre-treated (milled, calcined, and acidified) corn stover was mixed with sodium hydroxide powder of various weight ratios of corn stover ash: $\mathrm{NaOH}, 1.0: 0.5,1.0: 1.0,1.0: 1.5$, and 1.0:2.0 and heated at $300{ }^{\circ} \mathrm{C}$ for two hours to achieve a fused powder. This was cooled at room temperature and milled. The fused powder and deionized water mixture have a weight ratio of fused mass:deionized water of 1:2 and aged for two hours at room temperature with stirring. After which, the suspension was subjected to a centrifuge process then sieved to eradicate solid residue to achieve clear supernatant. Measurement of concentrations of $\mathrm{Si}, \mathrm{Al}$, and $\mathrm{Na}$ in the supernatant were made using inductively coupled plasma-atomic emission spectroscopy (ICP-AES SPS 7800) (SII Nano Technology Inc., Tokyo, Japan).

\subsubsection{Zeolite A Preparation}

The zeolite A synthesis was prepared using the silicon and aluminum in the supernatant; prior to this, its concentration was first measured using ICP-AES. A high silica supernatant and deionized water mixture was made using a weight ratio of silica supernatant:deionized water of 2:1. In the preparation of the reaction mixture of $\mathrm{Si} / \mathrm{Al}$ with a molar ratio of 1 , the diluted silica supernatant was blended with intermittent drops of a solution of sodium aluminate made from a gram of sodium aluminate powder into $5 \mathrm{~mL}$ of deionized water, while under vigorous stirring. This mixing was continued for an hour, then the hydrothermal treatment was carried out using a Teflon-lined stainless-steel vessel at $90^{\circ} \mathrm{C}$ for various times $(6.0,9.0,12.0 \mathrm{~h}$.) at a pressure that was autogenous. Finally, the 
zeolite A synthesis was filtered, washed several times with deionized water, and then dried under $100^{\circ} \mathrm{C}$ for twenty-four hours.
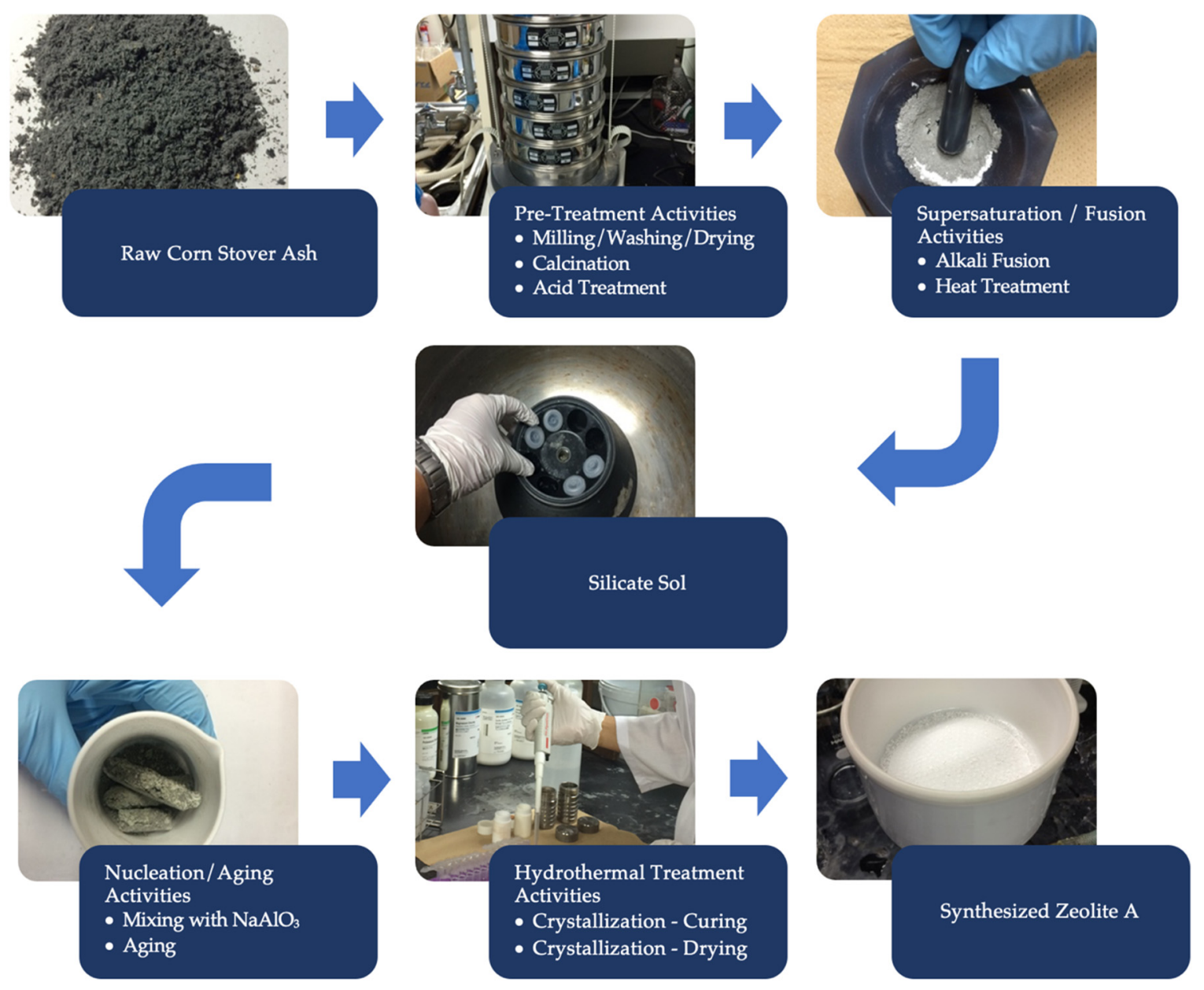

Figure 2. A schematic representation for the two-step zeolite A preparation method using corn stover ash.

\subsection{Characterizations and Cation Exchange Capacity (CEC)}

The elemental compositions of corn stover ash, specifically $\mathrm{Si}, \mathrm{Al}, \mathrm{Mg}, \mathrm{P}, \mathrm{K}, \mathrm{Ca}$, etc., were examined using X-ray fluorescence (XRF, Horiba XGT-7200, Horiba, Ltd., Kyoto, Japan). The $\mathrm{N}_{2}$ adsorptions of the corn stover ash and synthesized zeolite A were carried out using an Autosorb1C AX1C-MP-LP (Quantachrome Instruments, Boynton Beach, FL, USA) and the specific area was calculated using the BET method. The crystal phases of the powders were classified using the powder diffraction technique with a Multiplex (Rigaku, Tokyo, Japan) with Ni-filtered $\mathrm{Cu}-\mathrm{K} \alpha$ radiation $(\lambda=0.15418 \mathrm{~nm})$, operating at $40 \mathrm{kV}$ and $20 \mathrm{~mA}$ over the 2-theta range of $5^{\circ}$ to $90^{\circ}$. A Fourier transform infrared (FT-IR) spectrometer (Perkin Elmer, Waltham, MA, USA) equipped with a diffuse reflectance attachment was used for measuring the diffuse reflectance infrared Fourier transform spectroscopy (DRIFTS). Transmittance mode analyses were performed using the $\mathrm{KBr}$ pressed technique in $4000-400 \mathrm{~cm}^{-1}$ regions. The thermal stability of corn stover ash was carried out in air using thermogravimetry or TG-DTA Thermo plus TG 81200 (Rigaku, Tokyo, Japan) in the temperature range of $20^{\circ} \mathrm{C}-900{ }^{\circ} \mathrm{C}$ at a heating rate of $10^{\circ} \mathrm{C} / \mathrm{min}$. The morphologies of the corn stover ash, calcined and acid treated corn stover ash, and the obtained and commercial zeolite A were evaluated using the scanning electron microscopy (SEM VE-8800) (Keyence, Osaka, Japan) using Keyence VE-8800 with applied potentials of $5 \mathrm{kV}$ and $20 \mathrm{kV}$. The samples were coated with a thin layer of gold for the SEM measurements. 
Commercial and synthesized zeolite A was carried to its hydrogen form, which concurs with the standard procedure [48,70]. Under continuous stirring and at room temperature, commercial and synthesized zeolite A (one gram) was contacted for $2 \mathrm{~h}$ at $400 \mathrm{rpm}$ with $100 \mathrm{~mL}$ of $1.0 \mathrm{M} \mathrm{NH}_{4} \mathrm{Cl}$. The solid zeolite A was then separated from the liquid through filtration and again contacted with the new $1.0 \mathrm{M} \mathrm{NH}_{4} \mathrm{Cl}$ solution. This process was repeated 5 times. Consequently, the zeolite was dried at $550{ }^{\circ} \mathrm{C}$ for $3 \mathrm{~h}$, and again the same process which was formerly described was repeated and the zeolite was dried. Finally, the zeolite was washed with distilled water and dried at $80^{\circ} \mathrm{C}$ for $12 \mathrm{~h}$. Moreover, the cation exchange capacity (CEC) of commercial and synthesized zeolites were tested using the sodium acetate method so as to exchange all the cations in the material with sodium through the use of sodium acetate and then extract all of them using ammonium acetate. The extracted sodium ions were measured using inductively coupled plasma-atomic emission spectroscopy (ICP-AES) using SPS 7800 (SII).

\section{Results and Discussion}

\subsection{Characterization of Corn Stover Ash}

The chemical composition of the corn stover ash was determined by XRF and was as follows: Si was 62.17 wt. $\%, \mathrm{Al}$ was $4.72 \mathrm{wt} . \%, \mathrm{Mg}$ was $5.84 \mathrm{wt} . \%, \mathrm{P}$ was $6.85 \mathrm{wt} . \%$, $\mathrm{K}$ was 10.95 wt. $\%$, Ca was 7.47 wt. $\%$, Ti was 0.15 wt. $\%$, Mn was 0.05 wt. $\%$, Fe was 1.58 wt. $\%$, Cu was $0.01 \mathrm{wt} . \%$, Zn was $0.07 \mathrm{wt} . \%$, Sr was $0.02 \mathrm{wt} . \%$, and La was $0.12 \mathrm{wt} . \%$. The surface area of corn stover ash was $11.47 \mathrm{~m}^{2} / \mathrm{g}$. As shown in Figure 3, the XRD pattern of the corn stover ash confirmed the presence of characteristic peaks of calcite $\left(\mathrm{CaCO}_{3}\right)$, cristobalite high $\left(\mathrm{SiO}_{2}\right)$, and quartz $\left(\mathrm{SiO}_{2}\right)$. The broad peaks between $2 \theta$ of $20^{\circ}-50^{\circ}$ implied the presence of the amorphous phase of carbon and silica. The patterns were classified based on the characteristics of X-ray diffraction peaks with the d-values obtained with profile diffraction file (PDF) data. Raw corn stover ash (as received) matched the characteristic peaks of calcite with PDF\# 47-1743 and the characteristic peaks of cristobalite high $\left(\mathrm{SiO}_{2}\right)$ with PDF\# 85-0621 and quartz $\left(\mathrm{SiO}_{2}\right)$ with PDF\# 83-0539.

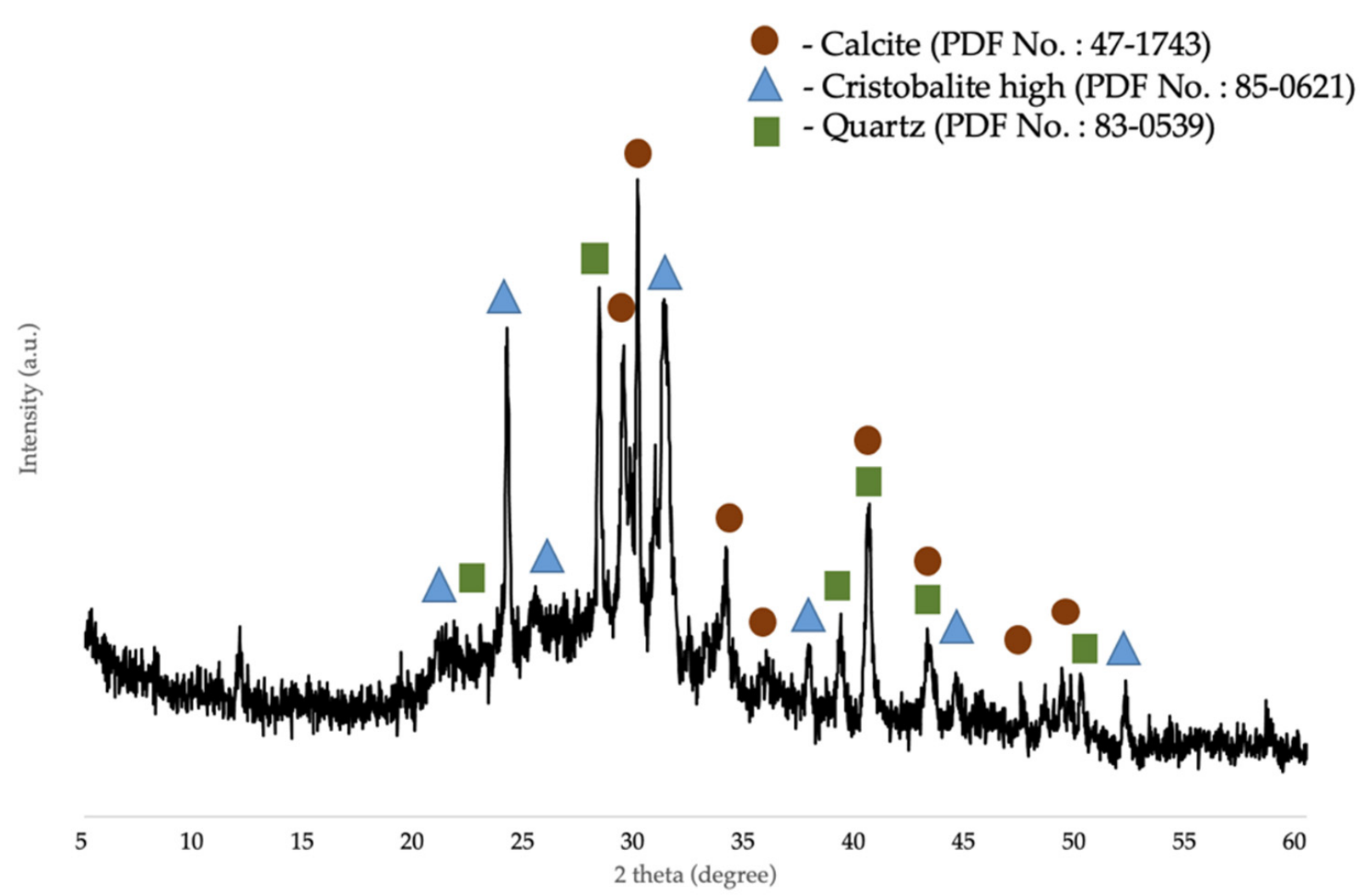

Figure 3. XRD patterns of raw corn stover ash (as received). 
Generally, the vibration of a particular configuration of chemical bonding is associated with its absorption bands. Published data from various studies [18,26,35,36,71,72] were used as a guide to interpret corn stover ash's spectra. As expected, the corn stover's FT-IR spectra revealed a comparable series of absorption bands; the main composition of the sample was oxide of $\mathrm{Si}$. The IR absorption bands and its associations to specific vibrations were gleaned as illustrated in Figure 4 and Table 1 . The peak at 1187 and $1063 \mathrm{~cm}^{-1}$ corresponded to the stretching vibrations of bridge bonds that were asymmetric $-\mathrm{v}_{\text {as }} \mathrm{T}-$ $\mathrm{O}(\mathrm{T})$ (Si-O stretching); the $1028 \mathrm{~cm}^{-1}$ belonged to the bending vibrations $-\mathrm{O}-\mathrm{H}$; the peak at $881 \mathrm{~cm}^{-1}$ has been assigned to Si translation; the peaks at 783,753,710, and $650 \mathrm{~cm}^{-1}$ were assigned to symmetrical stretching vibrations of bridge bonds $-\mathrm{v}_{\mathrm{S}} \mathrm{T}-\mathrm{O}-\mathrm{T}$ (vs $\mathrm{Si}-\mathrm{O}-\mathrm{Si}$ ); the peak of 581 matched the coordinated Al octahedral; and lastly, the peaks at 448, 502, and $540 \mathrm{~cm}^{-1}$ corresponded to bending vibrations $-\mathrm{T}-\mathrm{O}-\mathrm{T}$ or the deformation vibration of $\mathrm{Si}-\mathrm{O}$.

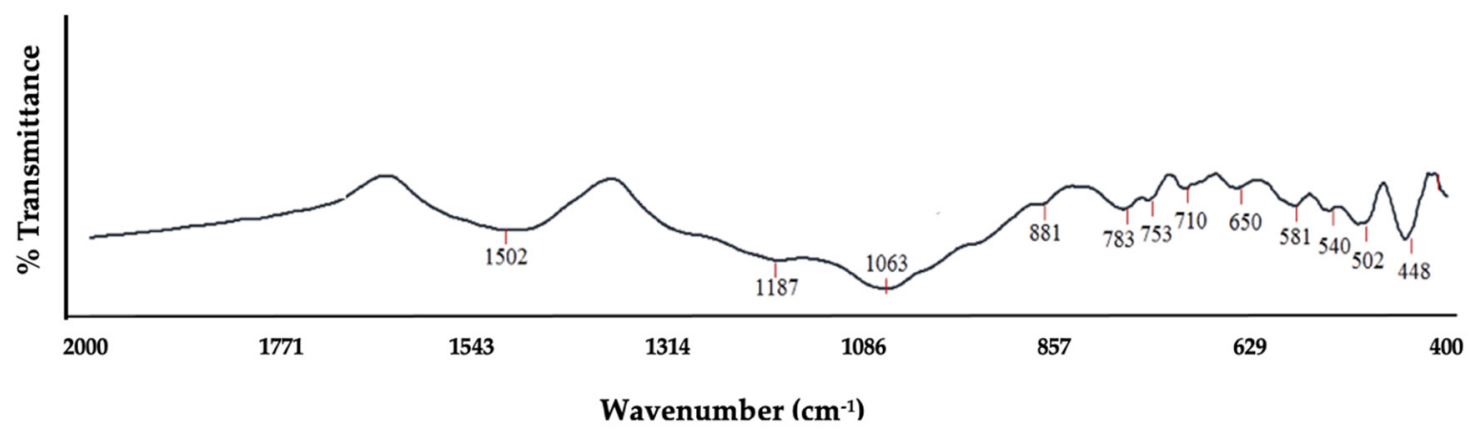

Figure 4. FT-IR spectra of raw corn stover ash (as received).

Table 1. IR vibrational frequencies of corn stover ash.

\begin{tabular}{|c|c|c|c|}
\hline Vibrations & Chemical Shift & Functionality & $\begin{array}{l}\text { Absorption Bands } \\
\qquad\left(\mathrm{cm}^{-1}\right)\end{array}$ \\
\hline $\begin{array}{l}\text { bending vibrations }-\mathrm{O}-\mathrm{T}-\mathrm{O} \\
\text { (deformation vibration of } \mathrm{Si}-\mathrm{O} \text { ) }\end{array}$ & & & $448,502,540$ \\
\hline coordinated Al octahedral & C-H Bend (medium) & Alkene & 581 \\
\hline bridge bonds & $\mathrm{Si}-\mathrm{O}$ & Silanol/Siloxane & $650,710,753,783$ \\
\hline$-\mathrm{v}_{\mathrm{s}} \mathrm{T}-\mathrm{O}-\mathrm{T}\left(\mathrm{v}_{\mathrm{s}} \mathrm{Si}-\mathrm{O}-\mathrm{Si}\right)$ & & & \\
\hline Si translation & C-H Bend (strong) & Aromatic & 881 \\
\hline Bending vibration $\mathrm{O}-\mathrm{H}$ & & $\mathrm{OH}$ & 1028 \\
\hline $\begin{array}{c}\text { asymmetric stretching vibrations of } \\
\text { bridge bonds }-\mathrm{v}_{\text {as }} \mathrm{T}-\mathrm{O}(\mathrm{T}) \\
\text { (Si-O stretching) }\end{array}$ & C-O Stretch (strong) & Ether/Alcohol & 1063,1187 \\
\hline
\end{tabular}

Figure 5 shows the SEM micrographs which illustrate the incidences of the corn stover ash achieved after pre-treatments, disclosing a noticeable modification in the morphology of the initial surface of the corn stover ash. The raw corn stover ash (as received) can be recognized by its honeycomb-like morphology (Figure 5a). Based on the SEM images in Figure $5 b, c$, the pre-treatments of calcining and acid leaching of corn stover ash cannot destroy the aggregation of its crystals; however, they were able to eradicate any impurities in the material, which resulted in a minor enhancement of the dispersibility of the corn stover ash crystals. The calcined-acid-treated corn stover ash honeycomb-like crystals disappeared instead, and a pile of irregular of microscopic particles was formed. 

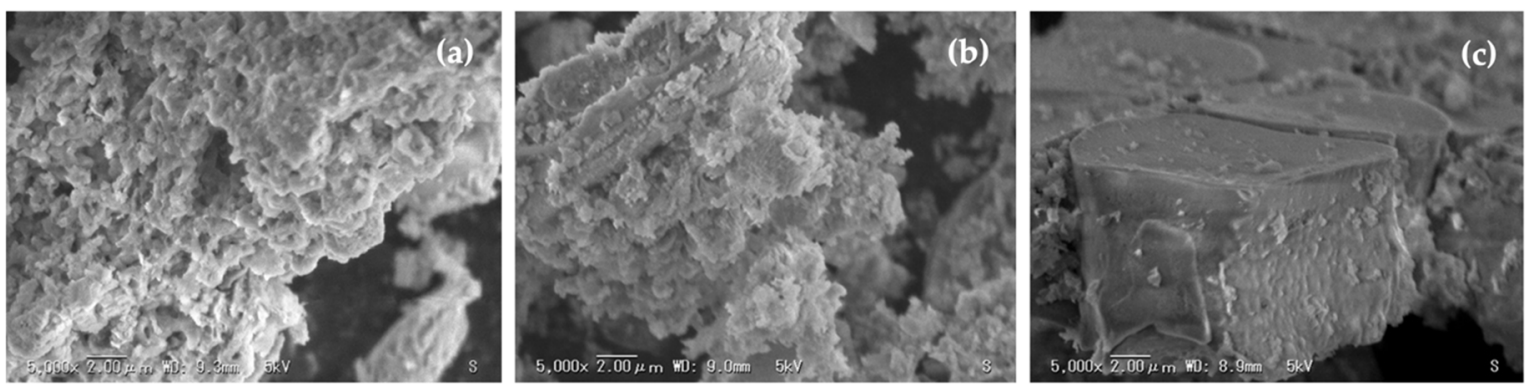

Figure 5. Morphologies of corn stover ash and related phases achieved by pretreatments. (a) Raw corn stover ash, as received, (b) calcined corn stover ash, and (c) acidified corn stover ash.

\subsection{The Effect of Calcination Temperature}

The initial step in zeolite A synthesis is the thermal treatment of the raw and purified corn stover ash to achieve a more reactive phase. Calcination is the process of removing volatile substances through the heating of solids to a high temperature; this is also known as the process of purification. It is a pretreatment given to corn stover ash with the goal of getting rid of the calcite. The calcite in the FTIR measurements shown in Figure 4 gives four peaks at 710,753 , and $783 \mathrm{~cm}^{-1}$, which match the symmetric in-plane bending, whereas the $881 \mathrm{~cm}^{-1}$ peak matches the asymmetric out-of-plane bending of $\mathrm{CO}_{3}$ groups. The $\mathrm{X}$-ray diffraction patterns of corn stover ash after calcination at different temperatures are shown in Figure 6. The characteristic peak of calcite at a $2 \theta$ value of $29.419^{\circ}$ was found in the diffractogram of the washed and milled corn stover ash. In the activation temperatures of $300{ }^{\circ} \mathrm{C}$ to $500{ }^{\circ} \mathrm{C}$, there was no major structural change observed or the calcite peak did not decompose. However, when activated at $600{ }^{\circ} \mathrm{C}$ there was a slight disappearance of the calcite peak. This disappearance was made even clearer when activated at $700{ }^{\circ} \mathrm{C}$. This result conforms with the study of Zunino et al. [73], stating that calcite decomposes between $600{ }^{\circ} \mathrm{C}$ and $800{ }^{\circ} \mathrm{C}$.

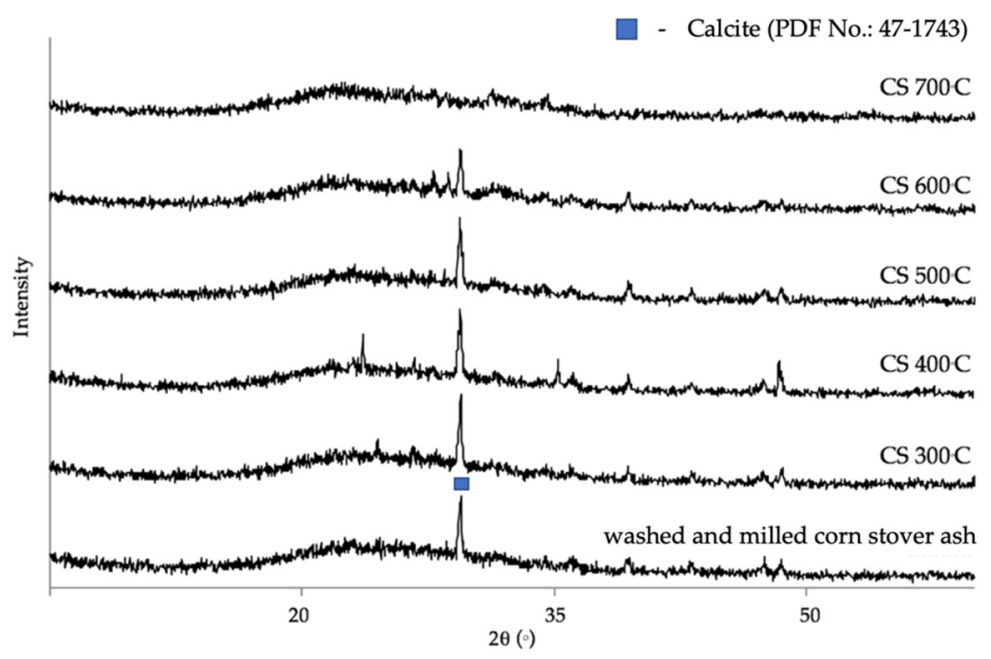

Figure 6. The XRD patterns of corn stover ash under different calcination temperatures.

The thermal stability of the initial corn stover was obtained via thermogravimetric analysis (TG-DTA), as shown in Figure 7. The transition of corn stover was detected near $500{ }^{\circ} \mathrm{C}$. The loss below $350^{\circ} \mathrm{C}$ corresponds to the corn stover water and the loss in the range of $350^{\circ} \mathrm{C}-550^{\circ} \mathrm{C}$ can be attributed to the dehydroxylation of the structural $\mathrm{OH}$ of the corn stover. 


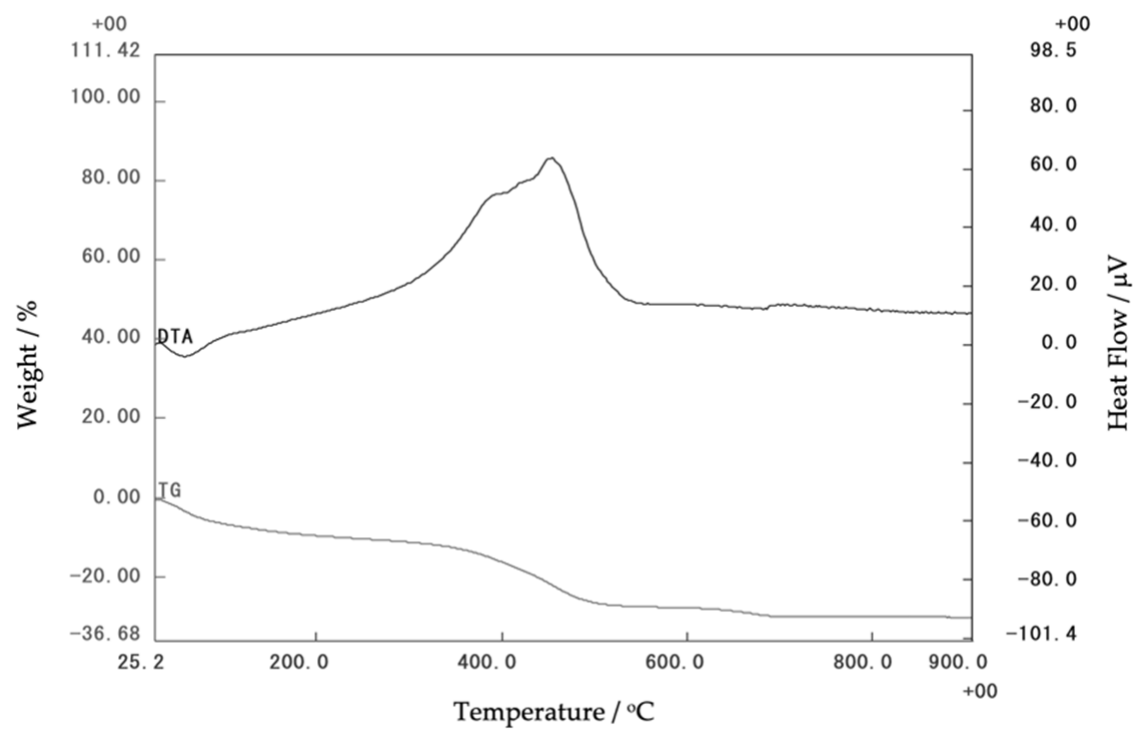

Figure 7. Thermogravimetric analysis of corn stover ash.

Figure 8 shows the FT-IR spectra of corn stover ash under different calcination temperatures. Comparing the IR signal spectra of the different determined thermal conditions, the presence of the $\mathrm{Si}-\mathrm{O}$ bond in multiple signals in the raw corn stover ash indicates the presence of a silanol, due to the presence of alcohol. However, in all higher thermal conditions, the presence of alcohol could not be observed; hence, this could indicate siloxane functionality of the $\mathrm{Si}-\mathrm{O}$ bond. In the absence of alcohol in higher thermal conditions, it could be implied that it was transformed into a carboxylic acid in higher thermal conditions in different signals; $1646 \mathrm{~cm}^{-1}$ at $300{ }^{\circ} \mathrm{C}, 1628 \mathrm{~cm}^{-1}$ at $400{ }^{\circ} \mathrm{C}$, and $1646 \mathrm{~cm}^{-1}$ at $500{ }^{\circ} \mathrm{C}-700{ }^{\circ} \mathrm{C}$, but was not present in the raw corn stover ash. This could be brought about by hydrolysis caused by calcination in higher thermal conditions, and this may also result in the presence of fewer silanols to bond to the terminal carboxylate.

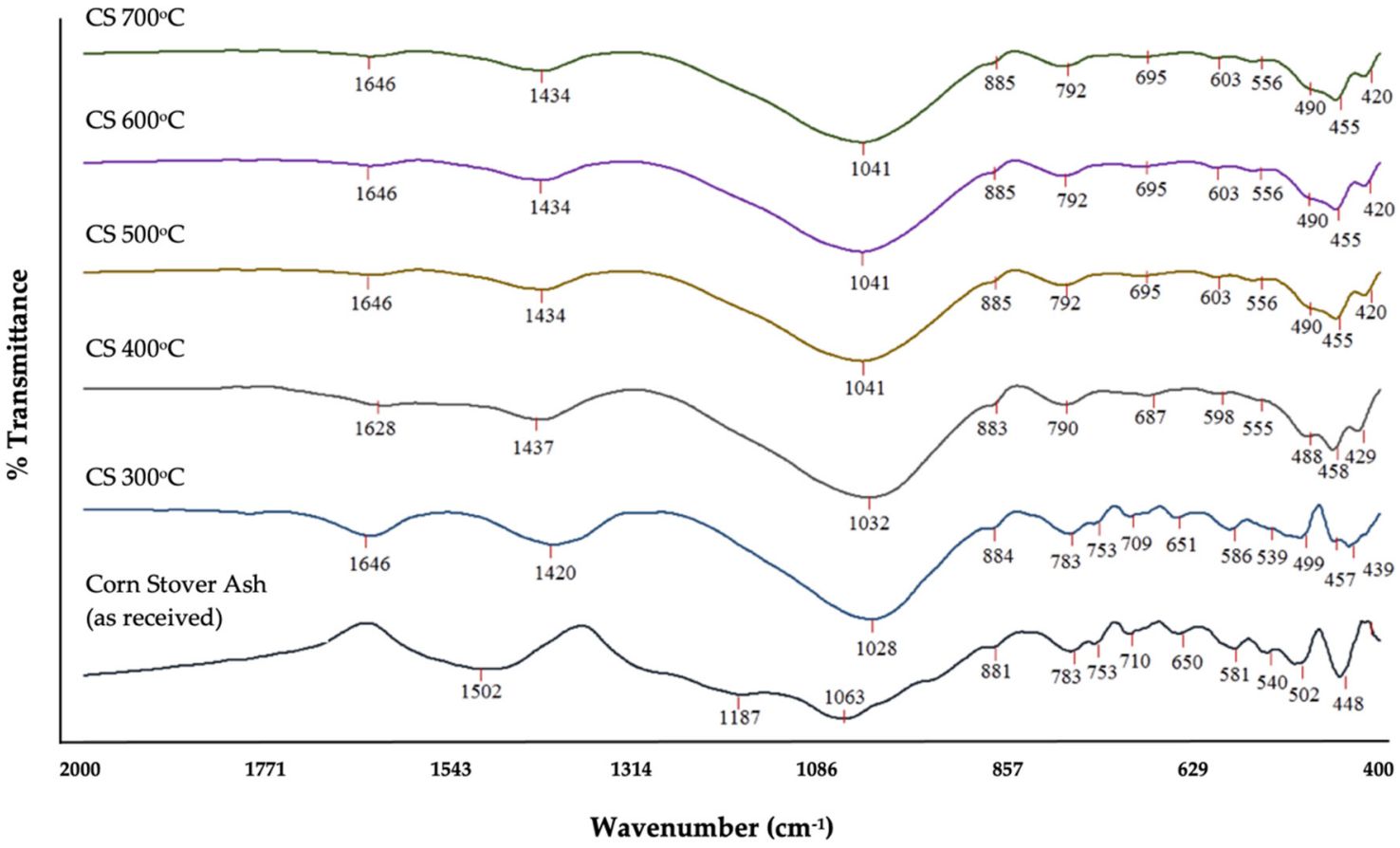

Figure 8. FT-IR spectra of corn stover ash under different calcination temperatures. 
All spectral signals in higher thermal conditions- $500{ }^{\circ} \mathrm{C}, 600{ }^{\circ} \mathrm{C}$, and $700{ }^{\circ} \mathrm{C}$ consecutively-had the same spectral reading, which may imply that by $500{ }^{\circ} \mathrm{C}$ all the decomposable functional groups under calcination had reached their satiation points and could no longer be transformed further. Hence, the presence of $\mathrm{Si}-\mathrm{O}$ bonds could not be decomposed by calcination.

Generally, the calcination temperature is chosen in the range that enables the complete transformation into the amorphous phase. From the thermodynamic point of view, the higher the calcination temperature, the better transformation can occur. However, there should be some balance struck between this and the economic reason-energy and effort resources. Therefore, the calcination temperature of $500{ }^{\circ} \mathrm{C}$ was chosen for the following experiment since it is high enough for the transformation and it only uses a lower amount of electrical power. The results further showed that synthesized zeolite A was obtained using a calcination temperature of $5000^{\circ} \mathrm{C}$ within two hours of airflow, which is much lower than the temperatures ranging from $550{ }^{\circ} \mathrm{C}-8000{ }^{\circ} \mathrm{C}$ reported in other studies of agricultural waste $[17,21]$ and other materials $[29,31,35-38,41]$.

\subsection{The Effect of Alkalinity}

One of the major determinant process, which is its concentration base, controls the crystallization of zeolites [29]. The alkalinity surge resulted in an increase in the rate of crystallization through crystal growth and nucleation, which are consequences of the rise in aluminate, silicate, and aluminosilicate concentrations $[39,47,74,75]$. The particle size decreases with this increase in alkalinity. This yields a narrow dispersal of particle size because of the rise in the rate of nucleation and polymerization between aluminate and polysilicate anions $[37,76,77]$.

The effects of the phase composition of synthesized zeolite A material were investigated with fusion ratios of corn stover ash: $\mathrm{NaOH}$ from $0.5,1.0,1.5$, and 2.0, respectively, at $500{ }^{\circ} \mathrm{C}$ with different curing times of $6,9,12$, and $24 \mathrm{~h}$. The growth of synthesized zeolite $\mathrm{A}$ in the samples was observed through the comparison of the $\mathrm{d}$-values of the products obtained from the PDF card no. 39-0222 and the d-values of commercial zeolite A samples. The most notable change detected in the XRD diffractograms is the presence of the characteristic peaks of zeolite A. The synthesized products matched the characteristic peaks of zeolite A at $2 \theta$ values of $7.200^{\circ}, 10.180^{\circ}, 12.461^{\circ}, 16.080^{\circ}, 21.640^{\circ}, 23.940^{\circ}, 26.060^{\circ}$, $27.061^{\circ}, 29.880^{\circ}, 30.778^{\circ}, 32.481^{\circ}, 33.319^{\circ}$, and $34.084^{\circ}$, respectively.

Figure 9 illustrates the XRD patterns of the treated corn stover ash samples with 0.5 to 2.0 ratios of weight of $\mathrm{NaOH}$ powder; zeolite $\mathrm{A}$ was determined to be the chief integral mineral phase and no hydroxysodalite was observed for the 0.5 to 1.0 fusion ratios. In the 1.5 fusion ratios of the 6-, 9-, 12-h curing times, no hydroxysodalite was observed; however, in the 24-h curing time, a few traces of hydroxysodalite with PDF card no. 1-72-2329 were observed at the $2 \theta$ value of $28.22^{\circ}$. These few traces of hydroxysodalite were also observed in the 2.0 fusion ratio in all its curing times $(9-, 12-$, and $24-\mathrm{h})$, set in the two $2 \theta$ regions, where one characteristic peak corresponded to zeolite $\mathrm{A}$ at $2 \theta$ values of $23.96^{\circ}$, which intensified, thereby manifesting the combination of zeolite A and hydroxysodalite. It was also observed that in the $24-\mathrm{h}$ curing time another $2 \theta$ region was manifested, with the value of $34.14^{\circ}$. 


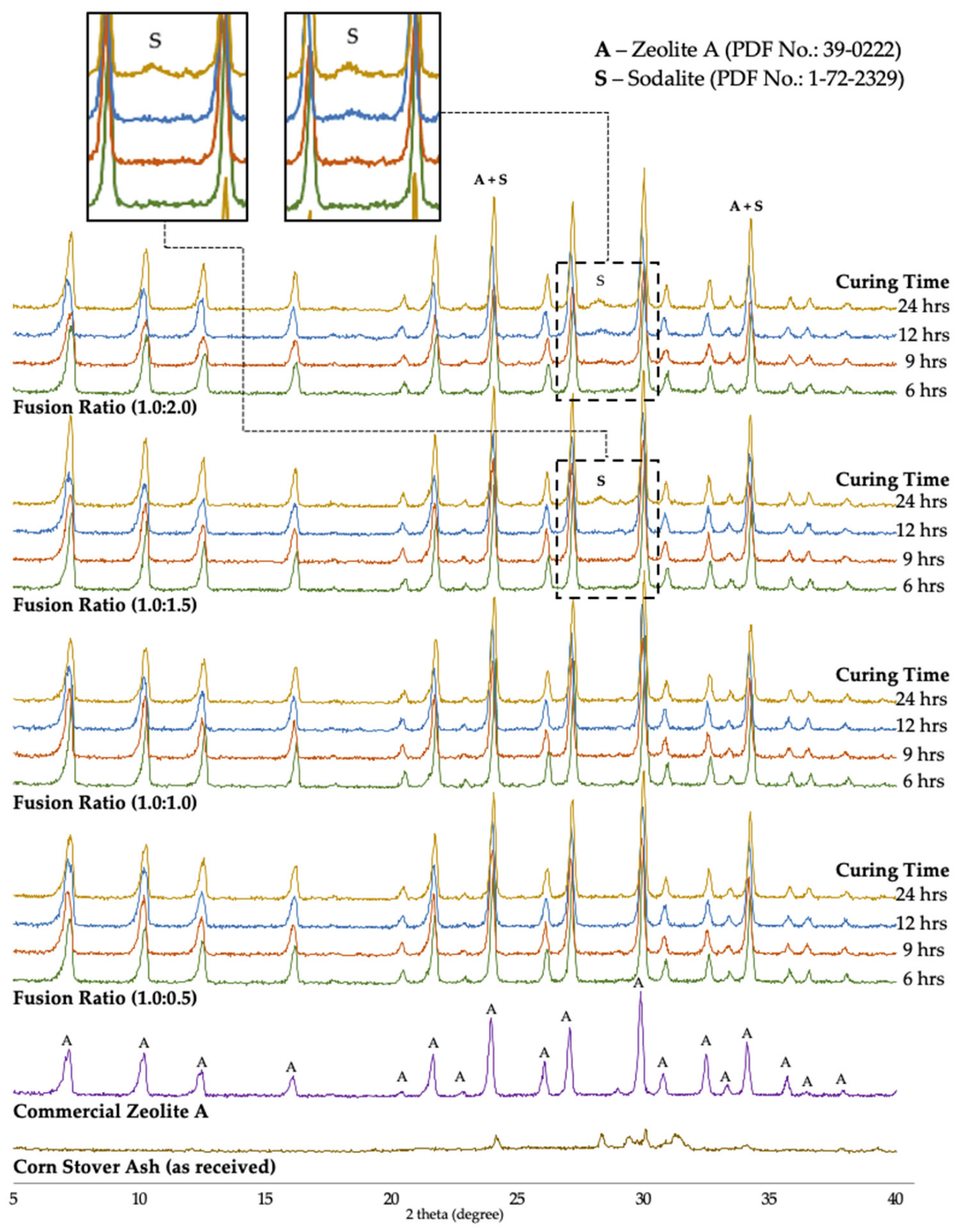

Figure 9. XRD patterns of raw corn stover ash (as received), commercial zeolite A, and synthesized zeolite A under different curing times achieved using different corn stover ash: $\mathrm{NaOH}$ ratios.

These results confirmed that moderate alkalinity conditions are significant in the crystallization of zeolite A. The literature revealed that any increase in the alkalinity boosts the silica source solubility. Likewise, an increase in the supersaturation degree of the 
hydrogel synthesis can give way to an increase in the rate of nucleation [78]. This leads to the fact that the rate of crystallization can be enhanced through an increase in alkalinity. On the contrary, alkalinity conditions that are too strong can suddenly transform synthesized zeolite A into hydroxysodalite. The fusion ratio of corn stover: $\mathrm{NaOH}$ of 2.0 yielded a mix of crystalline zeolite A and a few traces of hydroxysodalite. These XRD data illustrate that the intensities of the hydroxysodalite peaks in the pattern increased with the rise in the $\mathrm{NaOH}$ concentration. Similar observations were achieved by Andrades et al. [79], Belviso et al. [80], Cundy and Cox [81], Gougazeh and Buhl [36], Johnson et al. [40], Liu et al. [82], Mostafa et al. [83], and Youcef et al. [84] — synthesized zeolite A was achieved at concentrations that were of low base and the intensities decreased with concentrations that were of higher base.

\subsection{The Effect of Curing Time}

The effects of various curing times on the crystallization of zeolite A from corn stover ash during hydrothermal treatment were investigated. Figures 10-12 show the SEM micrographs of the incidences of the zeolitic products achieved after hydrothermal synthesis of corn stover ash with fusion ratios of 0.5 to 2.0 under different curing times. Cubic rounded-edge crystals with sizes ranging from $0.6 \mu \mathrm{m}$ to $2.0 \mu \mathrm{m}$ after hydrothermal treatment for different curing times can be seen in the synthesized zeolite A, verifying the materialization of zeolite A that is similar to commercial zeolite A.
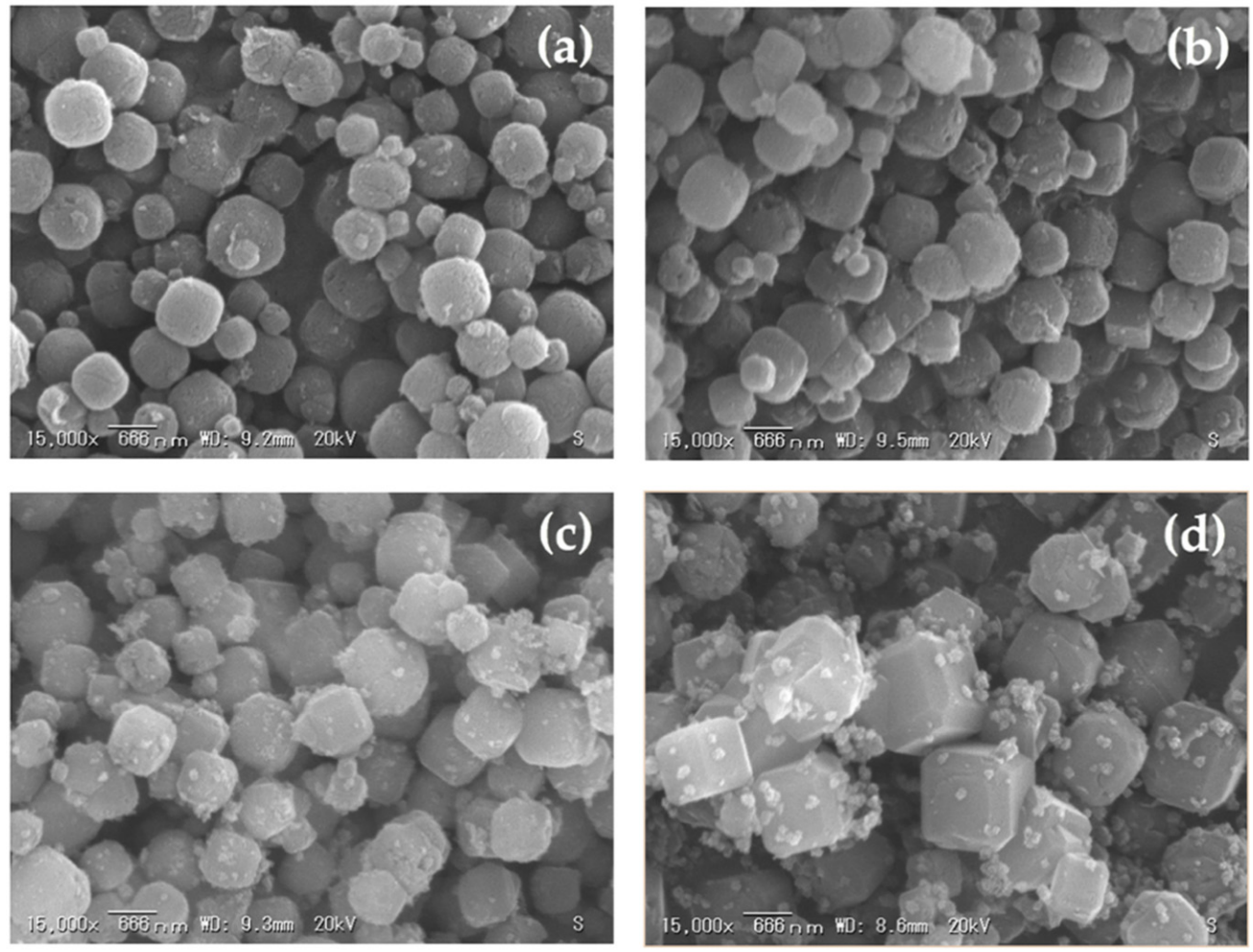

Figure 10. Morphologies of synthesized zeolite A with a curing time of $6.0 \mathrm{~h}$ and related phases achieved using different corn stover ash: $\mathrm{NaOH}$ ratios (a), corn stover ash: $\mathrm{NaOH}=1: 0.5$, (b) corn stover ash: $\mathrm{NaOH}=1: 1.0$, (c) corn stover ash: $\mathrm{NaOH}=1: 1.5$, (d) corn stover ash: $\mathrm{NaOH}=1: 2.0$. 

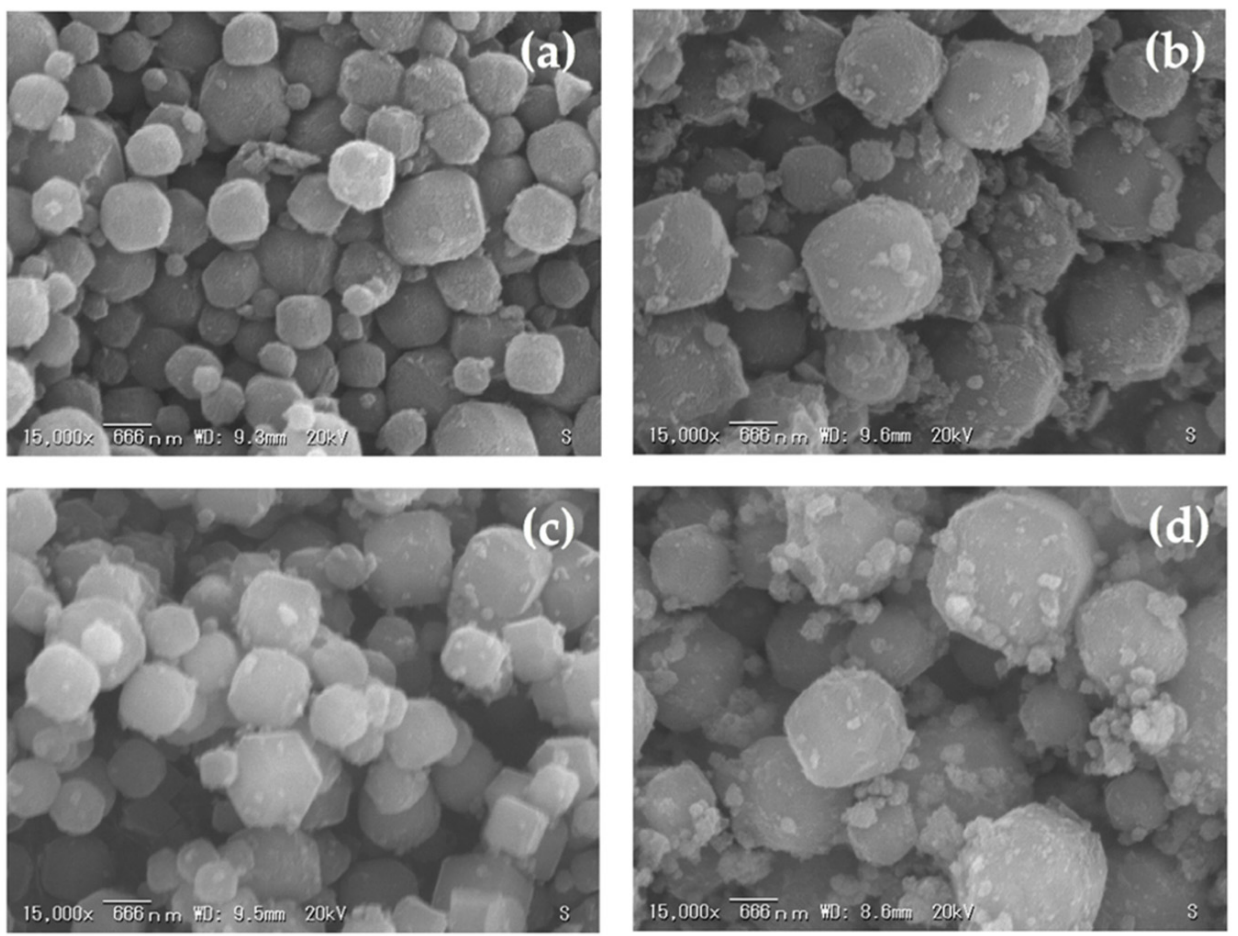

Figure 11. Morphologies of synthesized zeolite A with a curing time of $9.0 \mathrm{~h}$ and related phases achieved using different corn stover ash: $\mathrm{NaOH}$ ratios: (a) corn stover ash: $\mathrm{NaOH}=1: 0.5$, (b) corn stover ash: $\mathrm{NaOH}=1: 1.0,($ c) corn stover ash:NaOH = 1:1.5, (d) corn stover ash: $\mathrm{NaOH}=1: 2.0$.
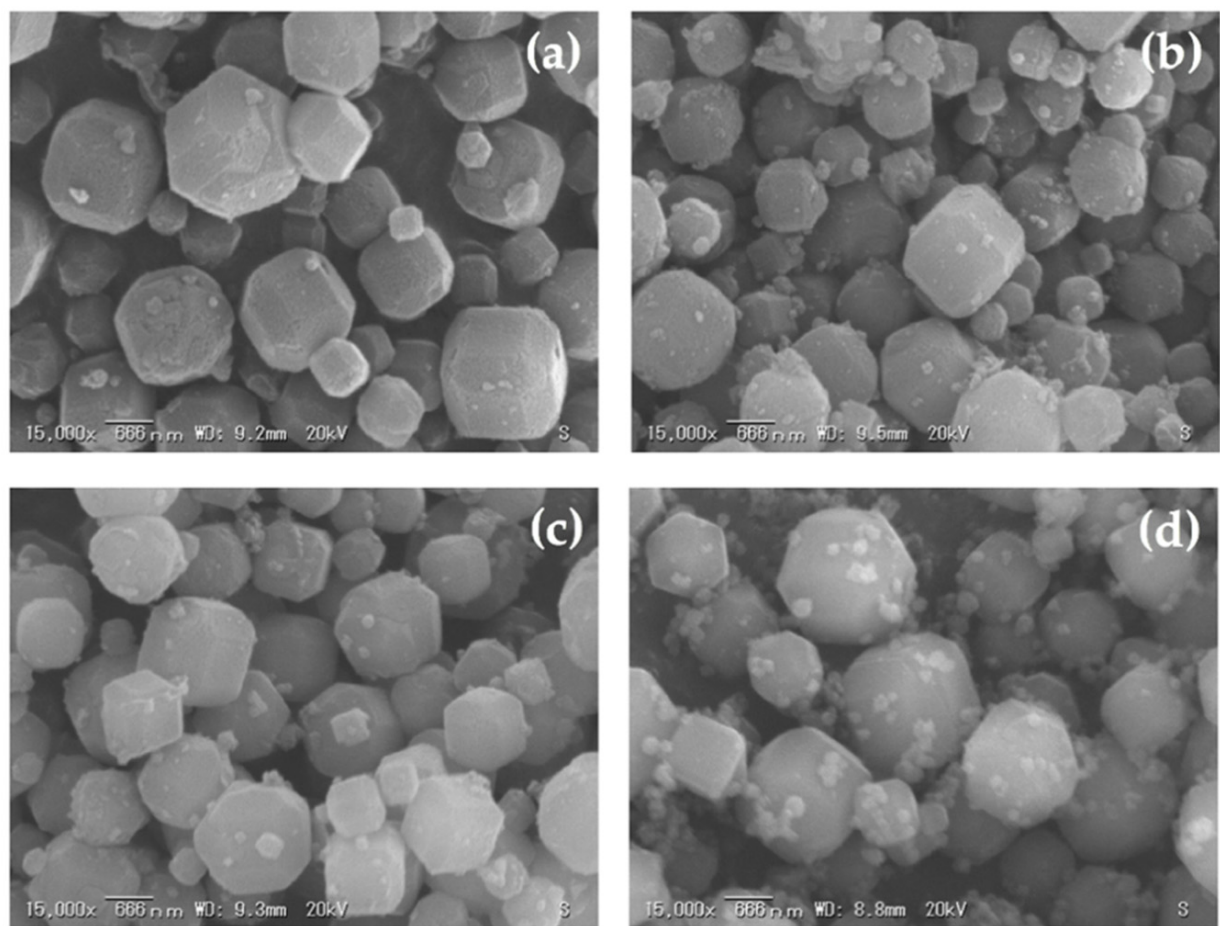

Figure 12. Morphologies of synthesized zeolite A with a curing time of $12.0 \mathrm{~h}$ and related phases achieved using different corn stover ash: $\mathrm{NaOH}$ ratios: (a) corn stover ash: $\mathrm{NaOH}=1: 0.5$, (b) corn stover ash: $\mathrm{NaOH}=1: 1.0$, (c) corn stover ash: $\mathrm{NaOH}=1: 1.5$, (d) corn stover ash: $\mathrm{NaOH}=1: 2.0$.

The SEM micrographs of the zeolites initially showed poorly crystalline zeolites. The cubic rounded-edge crystals did not manifest entirely in the 6-h curing time. However, 
in the 9- and 12-h curing times, we observed a similar morphology to that of synthesized zeolite A.

These results are in agreement with those of Ayele et al. [37], Ayele et al. [39], Purnomo et al. [26], and Zhang et al. [77], stating that the related actions of alkalinity and aluminum substances in the reaction mixtures are the bases of crystalline zeolite A's morphological characteristics. The alkalinity content extensively determines the size of the zeolite A crystals. This means that, as shown in the experiments conducted, the sample size of the zeolite A crystals exhibits a marginal decrease when there is an increase in alkali fusion.

The SEM micrographs illustrated in Figures $10 \mathrm{~d}, 11 \mathrm{~d}$ and $12 \mathrm{~d}$ showed no formation of spheroidal sodalite structures, as noted with increasing $\mathrm{NaOH}$ concentrations (fusion ratio of 2.0), which was expected. However, aggregates began to appear, which could imply the initial formation of hydroxysodalite structures. In the experimental results of this study, the observed morphologies were the same as those detailed in the previous studies $[36,41,43]$ and this correlates with the data obtained from the XRD results, as seen in Figure 9. Thus, the crystal size was decreased; this was brought forth by the rise in alkalinity and further expounded by the increase in nucleus numbers that occurred in the gel medium. This was also shown in the results gathered by Krznarić et al. [75], Mousavi et al. [85], and Xing Dong et al. [76]. On the other hand, unlike the significant effect of alkalinity on the morphology of the synthesized zeolite A from corn stover ash, the curing time does not have a notable effect on the synthesized zeolite A particle size. This result conforms with the observations made by Abdullahi et al. [86], Bayati et al. [87], and Johnson et al. [40].

The percentages of crystallinity of the synthesized zeolite A in various curing times and fusion ratios, calculated based on XRD profiles, are summarized in Table 2. The study showed that, for the synthesis of zeolite A using corn stover ash, the optimum crystallinity of $58.18 \%$ was attained with a fusion ratio of 1.0:1.5 and a curing time of $9.0 \mathrm{~h}$, which is of higher value compared with the percentage crystallinity of commercial zeolite $\mathrm{A}$, which is $53.51 \%$. Furthermore, among the percentage crystallinity values, the fusion ratio of 1.0:0.5 and curing time of $6.0 \mathrm{~h}$ gave the lowest value of $49.52 \%$. Comparing the trends of the percentages of crystallinity of the synthesized zeolite A samples revealed that there are upward patterns from 0.5 to 1.5 fusion ratios in different curing times. However, increasing the fusion ratio to 2.0 revealed a downward trend in all curing times, clearly showing that an increase in alkalinity corresponds to a decrease in crystallinity. This is congruent with the theory that a smaller particle size or crystallinity percentage can be found under more alkaline conditions. Obviously, the system has an additional $\mathrm{OH}$ concentration, and with this, more silicate and aluminate ions can be dissolved. Thus, there is a higher possibility for the crystallization of zeolite A.

Table 2. Percentage of crystallinity (\%CXRD) of zeolite A synthesized using various curing times and fusion ratios.

\begin{tabular}{ccccc}
\hline \multirow{2}{*}{ Curing Time (h) } & \multicolumn{4}{c}{ Fusion Ratios (Corn Stover Ash:NaOH) $\mathbf{m e q ~} \mathbf{~ N a}^{+} / \mathbf{g}$} \\
\cline { 2 - 5 } & $\mathbf{0 . 5 : 1 . 0}$ & $\mathbf{1 . 0 : 1 . 0}$ & $\mathbf{1 . 0 : 1 . 5}$ & $\mathbf{1 . 0 : 2 . 0}$ \\
\hline 6.0 & $49.52 \%$ & $52.38 \%$ & $56.64 \%$ & $51.26 \%$ \\
9.0 & $55.08 \%$ & $55.97 \%$ & $58.18 \%$ & $52.30 \%$ \\
12.0 & $51.80 \%$ & $52.73 \%$ & $55.01 \%$ & $50.50 \%$ \\
24.0 & $53.37 \%$ & $55.16 \%$ & $55.14 \%$ & $53.07 \%$ \\
\hline
\end{tabular}

Note: \%CXRD of commercial zeolite A-53.51\%.

\subsection{Cation Exchange Capacity (CEC)}

The key prerequisite for the application of zeolite A as an ion exchanger is its cation exchange capacity (CEC) $[39,44,88]$. Studies have generally revealed that a higher alumina content inside the crystalline structure explains the higher CEC potential of zeolite A. This adds to a huge surface negative charge, which can incorporate more cations [26] and a higher sodium content [89]. It is thus safe to conclude that the forthcoming application 
of zeolite samples can be solved by removing $\mathrm{Na}^{+}$ions and other cations from seawater. Table 3 illustrates the results obtained from this study pertaining to the removal capacity of sodium, expressed in meq $\mathrm{Na}^{+}$per gram of anhydrous commercial and synthesized zeolite A in hydrogen form.

Table 3. Cation exchange capacities of zeolite A synthesized using various curing times and fusion ratios.

\begin{tabular}{ccccc}
\hline \multirow{2}{*}{ Curing Time (h) } & \multicolumn{4}{c}{ Fusion Ratios (Corn Stover Ash:NaOH) $\mathbf{m e q ~ N a}^{+} / \mathbf{g}$} \\
\cline { 2 - 5 } & $\mathbf{0 . 5 : 1 . 0}$ & $\mathbf{1 . 0 : 1 . 0}$ & $\mathbf{1 . 0 : 1 . 5}$ & $\mathbf{1 . 0 : 2 . 0}$ \\
\hline 6.0 & 1.789 & 1.852 & 1.925 & 1.849 \\
9.0 & 1.827 & 2.142 & 2.439 & 2.275 \\
12.0 & 1.861 & 2.139 & 2.428 & 2.158 \\
\hline
\end{tabular}

Note: CEC of commercial zeolite $\mathrm{A}-1.641 \mathrm{meq} \mathrm{Na}^{+} / \mathrm{g}$.

The results show that as the fusion ratio escalates, the CEC values also increase, except for the fusion ratio of 1.0:2.0, because it shows a significant decrease in the observable CEC values in all of the different curing times. Theoretically, alkalinity is one of the most significant factors that controls the crystallinity of zeolites. The increase in alkalinity is the reason for the increase in crystallinity, through nucleation and crystal growth as a result of the high concentration of reactive aluminates and silicates. There is a parallelism in the increase in alkalinity and the decrease in particle size, resulting in a slight distribution of particle size because of the increase in the rate of polymerization and nucleation. Therefore, similarly, smaller particle size could lead to a higher CEC.

In addition, the results show the importance of curing time in synthesizing zeolite A with a higher crystallinity and a smaller morphology, which may lead to higher CEC values. The curing time of $9 \mathrm{~h}$ showed a predominantly higher CEC value compared to the 6- and 12-h curing times. However, among all the CEC results of the 9-h curing time, the 1.0:1.5 ratio achieved the highest cation exchange capacity of $2.439 \mathrm{meq} \mathrm{Na}^{+} / \mathrm{g}$ of synthesized anhydrous zeolite $\mathrm{A}$ as compared to other fusion ratios. This result conforms with the data presented in Table 2. Theoretically speaking, zeolite A loses its cation exchange capacity over time, which is a sign that the zeolite's negative charge was compensated partly by the adsorption of protons or any singly-charged or doubly-charged atoms from the solution, substituting one singly- or two singly-charged exchangeable atoms in the zeolite, respectively. The adsorption of these atoms into the zeolites is due to the greater selectivity of the zeolites toward them [90,91].

The commercial zeolite was also tested under the same conditions and resulted in a CEC performance of $1.641 \mathrm{meq} \mathrm{Na}^{+} / \mathrm{g}$; this result shows that the CEC performance obtained from all the different fusion ratios of corn stover ash: $\mathrm{NaOH}$ under different curing times, as seen in Table 3, were more favorable than that of the commercial zeolite. Even the lowest CEC performance among all the fusion ratios and curing times of the corn stover ash: $\mathrm{NaOH}$ product, with a fusion ratio at 0.5:1.0 and a curing time of $6.0 \mathrm{~h}$, showed a CEC performance of $1.789 \mathrm{meq} \mathrm{Na}^{+} / \mathrm{g}$. The works of Qian and $\mathrm{Li}$ [43] support these results, in that the CEC value increases at first, then decreases with the rise in the $\mathrm{NaOH}$ concentration and curing time, singly. Furthermore, the rise in cation exchange capacity, as shown in Table 3, is congruent with the rise in crystallinity of the synthesized zeolite A from corn stover ash, as can be gleaned from Table 2. This result is of great importance in zeolite crystallinity since it has promising applications in removing sodium ions from seawater.

\section{Conclusions}

Zeolite A was successfully synthesized from corn stover ash as the raw material, then fused with $\mathrm{NaOH}$ as the basis of various fusion ratios.

Among the set of different temperatures that can be used to calcinate the corn stover ash, it was found, based on the results of the FT-IR, that $500{ }^{\circ} \mathrm{C}$ is an optimal temperature to 
calcinate the ash. This result supports the TGA-DTA that showed a range of $350{ }^{\circ} \mathrm{C}-550{ }^{\circ} \mathrm{C}$ is needed for the dehydroxylation of the structural $\mathrm{OH}$ of corn stover ash.

The fusion ratio of 1.0:1.5 of corn stover ash: $\mathrm{NaOH}$ showed the most favorable result among the different fusion rates. Based on SEM and XRD analysis, the morphology of the synthesized zeolite in this ratio was more favorable, compared to that of 1.0:2.0 corn stover ash: $\mathrm{NaOH}$, despite the higher base concentration - this ratio resulted in the formation of a few traces of hydroxysodalite, which affected the CEC performance of the zeolite A.

The CEC performance also showed that the 1.0:1.5 ratio was the most favorable among the different fusion ratios, but among the different curing times, the 9-h curing time was the most favorable, yielding the highest CEC of 2.439 meq $\mathrm{Na}^{+} / \mathrm{g}$ of the synthesized anhydrous zeolite A. This curing time was also supported by the SEM results, showing more defined solids of cubic-rounded edge crystals. The CEC performance of all the different fusion ratios at different curing times of the corn stover ash: $\mathrm{NaOH}$ zeolite $\mathrm{A}$ was found to be more favorable than that of the commercial zeolite A (1.641 meq Na $/ \mathrm{g})$.

These results highlight the process performed in order to obtain zeolite A from corn stover ash, which can be utilized for the removal of sodium ions from seawater. In addition, corn stover ash has great potential as an economic raw material for the industrial production of zeolite A. We propose that alleviating environmental problems brought forth by the rise in agricultural waste from corn crops can be easily accomplished by converting these wastes into zeolites. After all, zeolites are considered to be very useful materials in a vast variety of fields, e.g., as ion exchangers, among other applications. Interestingly, future research could evaluate the efficacy of zeolite A from corn stover ash in various cation exchange processes, as ion exchangers, adsorbents, and catalysts.

Author Contributions: Conceptualization, N.P., S.G. and P.-a.G.; methodology, N.P., S.G., P.-a.G., W.K., H.H. and M.P.; software, N.P., W.K. and H.H.; validation, N.P., W.K. and H.H..; formal analysis, N.P.; investigation, N.P.; resources, W.K. and H.H.; data curation, N.P.; writing-original draft preparation, N.P.; writing—review and editing, N.P., S.G. and M.P.; visualization, N.P., S.G. and M.P.; supervision, N.P., W.K., H.H. and M.P.; project administration, N.P.; funding acquisition, N.P. All authors have read and agreed to the published version of the manuscript.

Funding: This research was funded by the Commission on Higher Education Faculty Development Program Phase 2 (CHED-FDP) of the Philippines through the Ph.D. Sandwich Program.

Institutional Review Board Statement: Not Applicable.

Informed Consent Statement: Not Applicable.

Data Availability Statement: The data underlying this article will be shared on reasonable request from the corresponding author.

Acknowledgments: The authors acknowledge the anonymous reviewers for their comments and suggestions that help improve the content of the paper. The authors would like also to extend their gratitude to the Commission on Higher Education Faculty Development Program Phase 2 (CHEDFDP) of the Philippines for the research funding and to Tokyo Institute of Technology-Department of International Development Engineering for providing research laboratory facilities.

Conflicts of Interest: The authors declare no conflict of interest.

\section{References}

1. Philippine Statistics Authority. Rice and Corn Situation and Outlook; Philippine Statistics Authority: Manila, Philippines, October 2018; pp. 1-7.

2. Habito, C.F.; Briones, R.M. Philippine agriculture over the years: Performance, policies and pitfalls. Agriculture $2005,38$.

3. Ranum, P.; Peña-Rosas, J.P.; Garcia-Casal, M.N. Global maize production, utilization, and consumption. Ann. N. Y. Acad. Sci. 2014, 1312, 105-112. [CrossRef] [PubMed]

4. Gerpacio, R.V.; Labios, J.D.; Labios, R.V.; Diangkinay, E.I. Maize in the Philippines: Production Systems, Constraints, and Research Priorities; Maize Production Systems Papers; CIMMYT International Maize and Wheat Improvement Center: Los Baños, Philippines, 2004.

5. Tanchuling, H. Issues and Prospects of the Philippine Corn Industry; Jessica Reyes-Cantos, J.S., Ed.; Rice Watch and Action Network: Quezon City, Philippines, 2007. 
6. $\quad$ Kriz, A.L.; Larkins, B.A. Molecular Genetic Approaches to Maize; Kriz, A.L., Larkins, B.A., Eds.; Springer Science \& Business Media: New Delhi, India, 2008; ISBN 9783540689225.

7. Prabha, S.; Durgalakshmi, D.; Rajendran, S.; Lichtfouse, E. Plant-derived silica nanoparticles and composites for biosensors, bioimaging, drug delivery and supercapacitors: A review. Environ. Chem. Lett. 2021, 19, 1667-1691. [CrossRef] [PubMed]

8. Permatasari, N.; Sucahya, T.N.; Dani Nandiyanto, A.B. Review: Agricultural Wastes as a Source of Silica Material. Indones. J. Sci. Technol. 2016, 1, 82. [CrossRef]

9. Adam, F.; Appaturi, J.N.; Iqbal, A. The utilization of rice husk silica as a catalyst: Review and recent progress. Catal. Today 2012, 190, 2-14. [CrossRef]

10. Nakashima, H.; Omae, K.; Takebayashi, T.; Ishizuka, C.; Uemura, T. Toxicity of silicon compounds in semiconductor industries. J. Occup. Health 1998, 40, 270-275. [CrossRef]

11. Petrov, I.; Michalev, T. Synthesis of Zeolite A: A Review. 2012, pp. 30-35. Available online: http:// citeseerx.ist.psu.edu/viewdoc/ download?doi=10.1.1.1049.109\&rep=rep1\&type=pdf (accessed on 27 August 2021).

12. Chen, S.; Yue, Q.; Gao, B.; Li, Q.; Xu, X. Preparation and characteristics of anion exchanger from corn stalks. Desalination 2011, 274, 113-119. [CrossRef]

13. Bohra, S.; Kundu, D.; Naskar, M.K. One-pot synthesis of NaA and NaP zeolite powders using agro-waste material and other low cost organic-free precursors. Ceram. Int. 2014, 40, 1229-1234. [CrossRef]

14. Farías, T.; de Ménorval, L.C.; Picazo, O.; Jordán, R. Ultrasonic and conventional synthesis of NaA zeolite from rice husk ash. J. Phys. Conf. Ser. 2017, 792, 12032. [CrossRef]

15. Petkowicz, D.I.; Rigo, R.T.; Radtke, C.; Pergher, S.B.; dos Santos, J.H.Z. Zeolite NaA from Brazilian chrysotile and rice husk. Microporous Mesoporous Mater. 2008, 116, 548-554. [CrossRef]

16. Santasnachok, C.; Kurniawan, W.; Hinode, H. The use of synthesized zeolites from power plant rice husk ash obtained from Thailand as adsorbent for cadmium contamination removal from zinc mining. J. Environ. Chem. Eng. 2015, 3, 2115-2126. [CrossRef]

17. Panpa, W.; Jinawath, S. Synthesis of ZSM-5 zeolite and silicalite from rice husk ash. Appl. Catal. B Environ. 2009, 90, 389-394. [CrossRef]

18. Saada, M.A.; Soulard, M.; Patarin, J.; Regis, R.C. Synthesis of zeolite materials from asbestos wastes: An economical approach. Microporous Mesoporous Mater. 2009, 122, 275-282. [CrossRef]

19. Mukherjee, S.; Barman, S.; Halder, G. Fluoride uptake by zeolite NaA synthesized from rice husk: Isotherm, kinetics, thermodynamics and cost estimation. Groundw. Sustain. Dev. 2018, 7, 39-47. [CrossRef]

20. Wang, Y.; Du, T.; Jia, H.; Qiu, Z.; Song, Y. Synthesis, characterization and CO2 adsorption of NaA, NaX and NaZSM-5 from rice husk ash. Solid State Sci. 2018, 86, 24-33. [CrossRef]

21. Maghfirah, A.; Ilmi, M.M.; Fajar, A.T.N.; Kadja, G.T.M. A review on the green synthesis of hierarchically porous zeolite. Mater. Today Chem. 2020, 17. [CrossRef]

22. Othman Ali, I.; Hassan, A.M.; Shaaban, S.M.; Soliman, K.S. Synthesis and characterization of ZSM-5 zeolite from rice husk ash and their adsorption of $\mathrm{Pb} 2+$ onto unmodified and surfactant-modified zeolite. Sep. Purif. Technol. 2011, 83, 38-44. [CrossRef]

23. Cheng, Y.; Lu, M.; Li, J.; Su, X.; Pan, S.; Jiao, C.; Feng, M. Synthesis of MCM-22 zeolite using rice husk as a silica source under varying-temperature conditions. J. Colloid Interface Sci. 2012, 369, 388-394. [CrossRef]

24. Katsuki, H.; Komarneni, S. Synthesis of Na-A and/or Na-X zeolite/porous carbon composites from carbonized rice husk. J. Solid State Chem. 2009, 182, 1749-1753. [CrossRef]

25. Moisés, M.P.; Da Silva, C.T.P.; Meneguin, J.G.; Girotto, E.M.; Radovanovic, E. Synthesis of zeolite NaA from sugarcane bagasse ash. Mater. Lett. 2013, 108, 243-246. [CrossRef]

26. Purnomo, C.W.; Salim, C.; Hinode, H. Synthesis of pure Na-X and Na-A zeolite from bagasse fly ash. Microporous Mesoporous Mater. 2012, 162, 6-13. [CrossRef]

27. Esmaeili, A.; Saremnia, B. Synthesis and characterization of NaA zeolite nanoparticles from Hordeum vulgare L. husk for the separation of total petroleum hydrocarbon by an adsorption process. J. Taiwan Inst. Chem. Eng. 2016, 61, 276-286. [CrossRef]

28. Tanaka, H.; Fujii, A. Effect of stirring on the dissolution of coal fly ash and synthesis of pure-form Na-A and -X zeolites by two-step process. Adv. Powder Technol. 2009, 20, 473-479. [CrossRef]

29. Fernandes Machado, N.R.C.; Miotto, D.M.M. Synthesis of Na-A and -X zeolites from oil shale ash. Fuel 2005, 84, 2289-2294. [CrossRef]

30. Ríos R., C.A.; Williams, C.D.; Roberts, C.L. A comparative study of two methods for the synthesis of fly ash-based sodium and potassium type zeolites. Fuel 2009, 88, 1403-1416. [CrossRef]

31. Izidoro, J.C.; Kim, M.C.; Bellelli, V.F.; Pane, M.C.; Botelho Junior, A.B.; Espinosa, D.C.R.; Tenório, J.A.S. Synthesis of zeolite A using the waste of iron mine tailings dam and its application for industrial effluent treatment. J. Sustain. Min. 2019, 18, 277-286. [CrossRef]

32. Hamadi, A.; Nabih, K. Synthesis of Zeolites Materials Using Fly Ash and Oil Shale Ash and Their Applications in Removing Heavy Metals from Aqueous Solutions. J. Chem. 2018, 2018, 6207910. [CrossRef]

33. Łach, M.; Grela, A.; Komar, N.; Mikuła, J.; Hebda, M. Calcined post-production waste as materials suitable for the hydrothermal synthesis of zeolites. Materials 2019, 12, 2742. [CrossRef]

34. Ginting, S.B.; Yulia, Y.; Wardono, H.; Darmansyah; Hanif, M.; Iryani, D.A. Synthesis and Characterization of Zeolite Lynde Type A (LTA): Effect of Aging Time. J. Phys. Conf. Ser. 2019, 1376. [CrossRef] 
35. Alkan, M.; Hopa, Ç.; Yilmaz, Z.; Güler, H. The effect of alkali concentration and solid/liquid ratio on the hydrothermal synthesis of zeolite NaA from natural kaolinite. Microporous Mesoporous Mater. 2005, 86, 176-184. [CrossRef]

36. Gougazeh, M.; Buhl, J.C. Synthesis and characterization of zeolite A by hydrothermal transformation of natural Jordanian kaolin. J. Assoc. Arab Univ. Basic Appl. Sci. 2014, 15, 35-42. [CrossRef]

37. Ayele, L.; Pérez-Pariente, J.; Chebude, Y.; Díaz, I. Conventional versus alkali fusion synthesis of zeolite A from low grade kaolin. Appl. Clay Sci. 2016, 132-133, 485-490. [CrossRef]

38. Maia, A.Á.B.; Dias, R.N.; Angélica, R.S.; Neves, R.F. Influence of an aging step on the synthesis of zeolite NaA from Brazilian Amazon kaolin waste. J. Mater. Res. Technol. 2019, 8, 2924-2929. [CrossRef]

39. Ayele, L.; Pérez-Pariente, J.; Chebude, Y.; Díaz, I. Synthesis of zeolite A from Ethiopian kaolin. Microporous Mesoporous Mater. 2015, 215, 29-36. [CrossRef]

40. Johnson, E.B.G.; Arshad, S.E. Hydrothermally synthesized zeolites based on kaolinite: A review. Appl. Clay Sci. 2014, 97-98, 215-221. [CrossRef]

41. Anuwattana, R.; Khummongkol, P. Conventional hydrothermal synthesis of Na-A zeolite from cupola slag and aluminum sludge. J. Hazard. Mater. 2009, 166, 227-232. [CrossRef] [PubMed]

42. Lee, M.G.; Park, J.W.; Kam, S.K.; Lee, C.H. Synthesis of Na-A zeolite from Jeju Island scoria using fusion/hydrothermal method. Chemosphere 2018, 207, 203-208. [CrossRef] [PubMed]

43. Qian, T.; Li, J. Synthesis of Na-A zeolite from coal gangue with the in-situ crystallization technique. Adv. Powder Technol. 2015, 26, 98-104. [CrossRef]

44. Collins, F.; Rozhkovskaya, A.; Outram, J.G.; Millar, G.J. A critical review of waste resources, synthesis, and applications for Zeolite LTA. Microporous Mesoporous Mater. 2020, 291, 109667. [CrossRef]

45. Rozhkovskaya, A.; Rajapakse, J.; Millar, G.J. Optimisation of zeolite LTA synthesis from alum sludge and the influence of the sludge source. J. Environ. Sci. (China) 2021, 99, 130-142. [CrossRef]

46. Payra, P.; Dutta, P.K. Zeolites: A Primer. ChemInform 2004, 35. [CrossRef]

47. Flanigen, E.M. Chapter 2 Zeolites and Molecular Sieves an Historical Perspective. Stud. Surf. Sci. Catal. 1991, 58, 13-34. [CrossRef]

48. Breck, D.W.; Breck, D.W. Zeolite Molecular Sieves: Structure, Chemistry, and Use; A Wiley-Interscience Publication; Wiley: Hoboken, NJ, USA, 1973; ISBN 9780471099857.

49. Chester, A.W.; Derouane, E.G. Zeolite Characterization and Catalysis, 5th ed.; Springer Science+Business Media B.V.: Dordrecht, The Netherlands, 2009; ISBN 9781402096778.

50. Mackinnon, I.D.R.; Millar, G.J.; Stolz, W. Hydrothermal syntheses of zeolite N from kaolin. Appl. Clay Sci. 2012, 58, 1-7. [CrossRef]

51. Geng, H.; Li, G.; Liu, D.; Liu, C. Rapid and efficient synthesis of CHA-type zeolite by interzeolite conversion of LTA-type zeolite in the presence of N, N, N-trimethyladamantammonium hydroxide. J. Solid State Chem. 2018, 265, 193-199. [CrossRef]

52. Mayoral, A.; Carey, T.; Anderson, P.A.; Diaz, I. Atomic resolution analysis of porous solids: A detailed study of silver ionexchanged zeolite A. Microporous Mesoporous Mater. 2013, 166, 117-122. [CrossRef]

53. Benaliouche, F.; Hidous, N.; Guerza, M.; Zouad, Y.; Boucheffa, Y. Characterization and water adsorption properties of Ag- and Zn-exchanged A zeolites. Microporous Mesoporous Mater. 2015, 209, 184-188. [CrossRef]

54. Ryu, T.; Kim, H.; Hong, S.B. Nature of active sites in Cu-LTA NH3-SCR catalysts: A comparative study with Cu-SSZ-13. Appl. Catal. B Environ. 2019, 245, 513-521. [CrossRef]

55. Xu, J.; Harold, M.P.; Balakotaiah, V. Modeling the effects of Pt loading on NOx storage on Pt/BaO/Al2O3 catalysts. Appl. Catal. B Environ. 2011, 104, 305-315. [CrossRef]

56. Tan, S.X.; Lim, S.; Ong, H.C.; Pang, Y.L. State of the art review on development of ultrasound-assisted catalytic transesterification process for biodiesel production. Fuel 2019, 235, 886-907. [CrossRef]

57. Mohan, N.; Cindrella, L. Template-free synthesis of Pt-MOx (M=Ni, Co \& Ce) supported on cubic zeolite-A and their catalytic role in methanol oxidation and oxygen reduction reactions characterized by the hydrodynamic study. Int. J. Hydrogen Energy 2017, 42, 21719-21731. [CrossRef]

58. Bin Lim, J.; Cha, S.H.; Hong, S.B. Direct N2O decomposition over iron-substituted small-pore zeolites with different pore topologies. Appl. Catal. B Environ. 2019, 243, 750-759. [CrossRef]

59. Cay-Durgun, P.; Fink, S.G.; Shabilla, A.; Yin, H.; Sasaki, K.A.; Lind, M.L. Analysis of the Water Permeability of Linde Type A Zeolites in Reverse Osmosis. Sep. Sci. Technol. 2014, 49, 2824-2833. [CrossRef]

60. Shirazian, S.; Ashrafizadeh, S.N. Synthesis of substrate-modified LTA zeolite membranes for dehydration of natural gas. Fuel 2015, 148, 112-119. [CrossRef]

61. Tokmachev, M.G.; Tikhonov, N.A.; Khamizov, R.K. Investigation of cyclic self-sustaining ion exchange process for softening water solutions on the basis of mathematical modeling. React. Funct. Polym. 2008, 68, 1245-1252. [CrossRef]

62. Bessa, R.; da Costa, L.S.; Oliveira, C.P.; Bohn, F.; Nascimento, R.; Sasaki, J.M.; Loiola, A.R. Kaolin-based magnetic zeolites A and P as water softeners. Microporous Mesoporous Mater. 2017, 245, 64-72. [CrossRef]

63. Millar, G.J.; Winnett, A.; Thompson, T.; Couperthwaite, S.J. Equilibrium studies of ammonium exchange with Australian natural zeolites. J. Water Process Eng. 2016, 9, 47-57. [CrossRef]

64. Djamel, N.; Samira, A. Mechanism of $\mathrm{Cu} 2+$ ions uptake process by synthetic NaA zeolite from aqueous solution: Characterization, Kinetic, intra-crystalline diffusion and thermodynamic studies. J. Mol. Liq. 2021, 323, 114642. [CrossRef] 
65. Hong, M.; Yu, L.; Wang, Y.; Zhang, J.; Chen, Z.; Dong, L.; Zan, Q.; Li, R. Heavy metal adsorption with zeolites: The role of hierarchical pore architecture. Chem. Eng. J. 2019, 359, 363-372. [CrossRef]

66. Abdelrahman, E.A. Synthesis of zeolite nanostructures from waste aluminum cans for efficient removal of malachite green dye from aqueous media. J. Mol. Liq. 2018, 253, 72-82. [CrossRef]

67. Mahmodi, G.; Dangwal, S.; Zarrintaj, P.; Zhu, M.; Mao, Y.; Mcllroy, D.N.; Reza Saeb, M.; Vatanpour, V.; Ramsey, J.D.; Kim, S.J NaA zeolite-coated meshes with tunable hydrophilicity for oil-water separation. Sep. Purif. Technol. 2020, 240, 116630. [CrossRef]

68. Mohamed, R.M.; Mkhalid, I.A.; Barakat, M.A. Rice husk ash as a renewable source for the production of zeolite NaY and its characterization. Arab. J. Chem. 2015, 8, 48-53. [CrossRef]

69. Chang, F.W.; Yang, H.C.; Roselin, L.S.; Kuo, W.Y. Ethanol dehydrogenation over copper catalysts on rice husk ash prepared by ion exchange. Appl. Catal. A Gen. 2006, 304, 30-39. [CrossRef]

70. Sannino, F.; Ruocco, S.; Marocco, A.; Esposito, S.; Pansini, M. Cyclic process of simazine removal from waters by adsorption on zeolite H-Y and its regeneration by thermal treatment. J. Hazard. Mater. 2012, 229-230, 354-360. [CrossRef]

71. Pavia, D.L.; Lampman, G.M.; Kriz, G.S.; Vyvyan, J.R. Introduction to Spectroscopy, 4th ed.; Brooks/Cole Cengage Learning: Belmont, CA, USA, 2010; ISBN 9780495114789.

72. Evi, M.; Sari, F.; Prasetyoko, D. Direct Synthesis of Sodalite from Kaolin: The Influence of Alkalinity. Indones. J. Chem. 2018, 18, 607-613. [CrossRef]

73. Zunino, F.; Boehm-Courjault, E.; Scrivener, K. The impact of calcite impurities in clays containing kaolinite on their reactivity in cement after calcination. Mater. Struct. Constr. 2020, 53. [CrossRef]

74. Auerbach, S.M.; Carrado, K.A.; Dutta, P.K. Handbook of Zeolite Science and Technology; CRC Press: Boca Raton, FL, USA, 2003; ISBN 9780203911167.

75. Krznarić, I.; Antonić, T.; Subotić, B.; Babić-Ivančić, V. Results of thermal and hydrothermal treatment of the aluminosilicate gels prepared at different batch concentrations. Thermochim. Acta 1998, 317, 73-84. [CrossRef]

76. Liu, X.D.; Wang, Y.P.; Cui, X.M.; He, Y.; Mao, J. Influence of synthesis parameters on NaA zeolite crystals. Powder Technol. 2013, 243, 184-193. [CrossRef]

77. Zhang, X.; Tong, D.; Jia, W.; Tang, D.; Li, X.; Yang, R. Studies on room-temperature synthesis of zeolite NaA. Mater. Res. Bull. 2014, 52, 96-102. [CrossRef]

78. Bronić, J.; Palčić, A.; Subotić, B.; Itani, L.; Valtchev, V. Influence of alkalinity of the starting system on size and morphology of the zeolite A crystals. Mater. Chem. Phys. 2012, 132, 973-976. [CrossRef]

79. Andrades, R.C.; Neves, R.F.; Diaz, F.R.V.; Júnior, A.H.M. Influence of alkalinity on the synthesis of zeolite A and hydroxysodalite from metakaolin. J. Nano Res. 2020, 61, 51-60. [CrossRef]

80. Belviso, C.; Giannossa, L.C.; Huertas, F.J.; Lettino, A.; Mangone, A.; Fiore, S. Synthesis of zeolites at low temperatures in fly ash-kaolinite mixtures. Microporous Mesoporous Mater. 2015, 212, 35-47. [CrossRef]

81. Cundy, C.S.; Cox, P.A. The hydrothermal synthesis of zeolites: Precursors, intermediates and reaction mechanism. Microporous Mesoporous Mater. 2005, 82, 1-78. [CrossRef]

82. Liu, H.; Peng, S.; Shu, L.; Chen, T.; Bao, T.; Frost, R.L. Magnetic zeolite NaA: Synthesis, characterization based on metakaolin and its application for the removal of $\mathrm{Cu} 2+, \mathrm{Pb} 2+$. Chemosphere 2013, 91, 1539-1546. [CrossRef]

83. Mostafa, A.A.; Youssef, H.F.; Materials, A. Utilization of Egyptian kaolin for Zeolite-A Preparation and Performance Evaluation. Int. Conf. Environ. Sci. Technol. 2011, 6, 43-48.

84. Dali Youcef, L.; López-Galindo, A.; Verdugo-Escamilla, C.; Belaroui, L.S. Synthesis and characterization of zeolite LTA by hydrothermal transformation of a natural Algerian palygorskite. Appl. Clay Sci. 2020, 193, 105690. [CrossRef]

85. Mousavi, S.F.; Jafari, M.; Kazemimoghadam, M.; Mohammadi, T. Template free crystallization of zeolite Rho via Hydrothermal synthesis: Effects of synthesis time, synthesis temperature, water content and alkalinity. Ceram. Int. 2013, 39, 7149-7158. [CrossRef]

86. Abdullahi, T.; Harun, Z.; Othman, M.H.D. A review on sustainable synthesis of zeolite from kaolinite resources via hydrothermal process. Adv. Powder Technol. 2017, 28, 1827-1840. [CrossRef]

87. Bayati, B.; Babaluo, A.A.; Karimi, R. Hydrothermal synthesis of nanostructure NaA zeolite: The effect of synthesis parameters on zeolite seed size and crystallinity. J. Eur. Ceram. Soc. 2008, 28, 2653-2657. [CrossRef]

88. Loiola, A.R.; Andrade, J.C.R.A.; Sasaki, J.M.; da Silva, L.R.D. Structural analysis of zeolite NaA synthesized by a cost-effective hydrothermal method using kaolin and its use as water softener. J. Colloid Interface Sci. 2012, 367, 34-39. [CrossRef]

89. Khaleque, A.; Alam, M.M.; Hoque, M.; Mondal, S.; Bin Haider, J.; Xu, B.; Johir, M.A.H.; Karmakar, A.K.; Zhou, J.L.; Ahmed, M.B.; et al. Zeolite synthesis from low-cost materials and environmental applications: A review. Environ. Adv. 2020, 2, 100019. [CrossRef]

90. Munthali, M.W.; Kabwadza-Corner, P.; Johan, E.; Matsue, N. Decrease in Cation Exchange Capacity of Zeolites at Neutral pH: Examples and Proposals of a Determination Method. J. Mater. Sci. Chem. Eng. 2014, 2, 1-5. [CrossRef]

91. Kumar, S.; Jain, S. History, introduction, and kinetics of ion exchange materials. J. Chem. 2013, 2013, 957647. [CrossRef] 